2009s-20

\title{
Risk Aversion, Intertemporal Substitution, and the Term Structure of Interest Rates
}

\author{
René Garcia, Richard Luger
}

\begin{tabular}{c}
\hline Série Scientifique \\
Scientific Series
\end{tabular}

Montréal
Mai 2009

(C) 2009 René Garcia, Richard Luger. Tous droits réservés. All rights reserved. Reproduction partielle permise

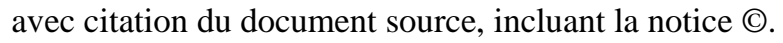

Short sections may be quoted without explicit permission, if full credit, including $₫$ notice, is given to the source.
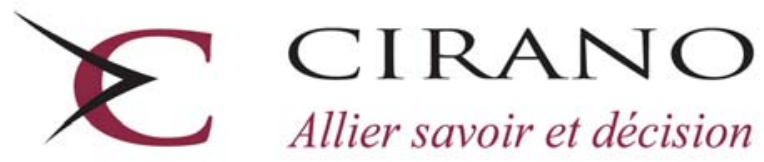

Allier savoir et décision

Centre interuniversitaire de recherche en analyse des organisations 


\section{CIRANO}

Le CIRANO est un organisme sans but lucratif constitué en vertu de la Loi des compagnies du Québec. Le financement de son infrastructure et de ses activités de recherche provient des cotisations de ses organisations-membres, d'une subvention d’infrastructure du Ministère du Développement économique et régional et de la Recherche, de même que des subventions et mandats obtenus par ses équipes de recherche.

CIRANO is a private non-profit organization incorporated under the Québec Companies Act. Its infrastructure and research activities are funded through fees paid by member organizations, an infrastructure grant from the Ministère du Développement économique et régional et de la Recherche, and grants and research mandates obtained by its research teams.

\section{Les partenaires du CIRANO}

\section{Partenaire majeur}

Ministère du Développement économique, de l’Innovation et de l’Exportation

\section{Partenaires corporatifs}

Banque de développement du Canada

Banque du Canada

Banque Laurentienne du Canada

Banque Nationale du Canada

Banque Royale du Canada

Banque Scotia

Bell Canada

BMO Groupe financier

Caisse de dépôt et placement du Québec

DMR

Fédération des caisses Desjardins du Québec

Gaz de France

Gaz Métro

Hydro-Québec

Industrie Canada

Investissements PSP

Ministère des Finances du Québec

Power Corporation du Canada

Raymond Chabot Grant Thornton

Rio Tinto Alcan

State Street Global Advisors

Transat A.T.

Ville de Montréal

\section{Partenaires universitaires}

École Polytechnique de Montréal

HEC Montréal

McGill University

Université Concordia

Université de Montréal

Université de Sherbrooke

Université du Québec

Université du Québec à Montréal

Université Laval

Le CIRANO collabore avec de nombreux centres et chaires de recherche universitaires dont on peut consulter la liste sur son site web.

Les cahiers de la série scientifique (CS) visent à rendre accessibles des résultats de recherche effectuée au CIRANO afin de susciter échanges et commentaires. Ces cahiers sont écrits dans le style des publications scientifiques. Les idées et les opinions émises sont sous l'unique responsabilité des auteurs et ne représentent pas nécessairement les positions du CIRANO ou de ses partenaires.

This paper presents research carried out at CIRANO and aims at encouraging discussion and comment. The observations and viewpoints expressed are the sole responsibility of the authors. They do not necessarily represent positions of CIRANO or its partners. 


\title{
Risk Aversion, Intertemporal Substitution, and the Term Structure of Interest Rates
}

\author{
René Garcia ${ }^{\dagger}$, Richard Luger ${ }^{\ddagger}$
}

\begin{abstract}
Résumé / Abstract
Nous construisons et évaluons un modèle d'équilibre de la structure par terme des taux d'intérêt, fondé sur une caractéristique de la fonction d'utilité récursive. Nous le comparons à un modèle caractérisé par l'absence d'arbitrage, dans lequel les prix du risque sont estimés librement sans contrainte de préférence. Dans les deux modèles, les rendements des obligations nominales sont des fonctions affines des variables d'état macroéconomique. Le modèle d'équilibre prend en compte le profil en forme de tente (tent-shaped) et l'ampleur des coefficients de régression prédictive relatifs aux rendements des obligations excédant les taux d'intérêt à terme, de même que le profil en forme de bosse (hump-shaped) dans la structure par terme des volatilités, tandis que le modèle à forme réduite et caractérisé par l'absence d'arbitrage ne tient pas compte de ces caractéristiques importantes de la courbe de rendement.
\end{abstract}

Mots clés : Utilité récursive, courbe de rendement, modèle macrofinancier affine, prime de risque liée aux obligations, perplexité des attentes.

We build and estimate an equilibrium model of the term structure of interest rates based on a recursive utility specification. We contrast it with an arbitrage-free model, where prices of risk are estimated freely without preference constraints. In both models, nominal bond yields are affine functions of macroeconomic state variables. The equilibrium model accounts for the tent-shaped pattern and magnitude of coefficients from predictive regressions of excess bond returns on forward rates and the hump-shaped pattern in the term structure of volatilities, while the reduced-form no-arbitrage model does not account for these important features of the yield curve.

Keywords: Recursive utility, Yield curve, Affine macro-finance model, Bond risk premium, Expectations puzzle.

Codes JEL : E43, E44, G12

\footnotetext{
* The first author is a research Fellow of CIRANO and CIREQ. He gratefully acknowledges financial support from the Bank of Canada, the Fonds de la Formation de Chercheurs et l’Aide `a la Recherche du Québec (FCAR), the Social Sciences and Humanities Research Council of Canada (SSHRC), and the MITACS Network of Centres of Excellence. We would like to thank seminar participants at HEC Lausanne, the 2007 CIREQ Financial Econometrics Conference, the 2007 Annual Meeting of the Canadian Economics Association, the 2007 Annual Meeting of the European Finance Association, the 2007 North American Summer Meeting of the Econometric Society, the 2007 European Meeting of the Econometric Society, CEMFI in Madrid, Spain, and at North Carolina State University.

† Corresponding author. Tel.: +33493187802; Fax: +33493187841; E-mail address: rene.garcia@edhec.edu Edhec Business School, 393 Promenade des Anglais, C.P. 3116, 06202, Nice, Cedex 3, France.

‡ Department of Economics, Emory University, Atlanta, GA 30322-2240, USA.
} 


\section{Introduction}

Most recent models of the term structure of interest rates are formulated in an arbitrage-free framework, whereby bond yields are affine functions of a number of observed and unobserved state variables that capture the sources of uncertainty in the economy. When only three latent factors are specified, the traditional interpretation following Litterman and Scheinkman (1991) links them to the level, slope, and curvature of the yield curve. ${ }^{2}$ Recently, observable macroeconomic variables have been added to the latent factors to try to understand the channels through which the economy influences the term structure, and not simply describe or forecast the movements of the term structure. Ang and Piazzesi (2003), Ang, Dong, and Piazzesi (2004), and Ang, Piazzesi, and Wei (2006) introduce measures of inflation and real activity as macroeconomic factors. The joint dynamics of these macro factors and the latent factors are captured by vector-autoregression (VAR) models. ${ }^{3}$

In these models based only on the absence of arbitrage, risk premiums for the various sources of uncertainty are obtained by specifying time-varying prices of risk that transform the riskfactor volatilities into premiums. The prices of risk, however, are estimated directly from the data without accounting for the fact that investors' preferences and technology should impose some constraints between these prices.

Our first contribution is to build a flexible equilibrium term structure model that accounts for the fact that the preferences of the representative agent will determine consistent risk premiums for all the risk factors that affect bonds. In terms of preferences, the model has two key features. First, the subjective discount factor is time-varying. Preferences with time-varying rates of time preference were introduced by Uzawa (1968) and have been extended by Epstein $(1983,1987)$. In those specifications, the subjective discount factor is a function of consumption so that the marginal utility of consumption in a given period can vary with consumption in other periods. Here we follow Obstfeld (1990) and link the subjective discount factor to the short-term rate of interest. A second key feature is a recursive utility structure, where the coefficient of relative

\footnotetext{
${ }^{2}$ Dai and Singleton (2003) and Piazzesi (2005) provide thorough surveys of this class of models.

${ }^{3}$ More structural models have also been proposed to explore the dynamic interaction between the macroeconomy and the term structure. See in particular Hördahl, Tristani, and Vestin (2006), Rudebusch and Wu (2004), and Bekaert, Cho, and Moreno (2003). These models combine the affine arbitrage-free dynamics for yields with a new Keynesian macroeconomic model, which typically consists of a monetary policy reaction function, an output equation, and an inflation equation. Diebold, Rudebusch, and Aruoba (2006) propose a dynamic Nelson-Siegel empirical model of the term structure, complemented by a VAR model for real activity, inflation, and a monetary policy instrument.
} 
risk aversion (CRRA) is disentangled from the elasticity of intertemporal substitution (EIS). We show that these two ingredients are necessary to explain bond risk premiums. ${ }^{4}$

In order to make our model comparable with arbitrage-free models and with that of Ang, Piazzesi, and Wei (2006) in particular, we use a VAR description of macroeconomic dynamics and we link them to those of the term structure so that nominal bond yields are affine functions of observable state variables. We specify a first-order VAR comprising the short-term rate of interest, the five-year term spread, a measure of the return on the equity market portfolio, the rate of inflation, and the rate of consumption growth. A distinct addition to the VAR model used in Ang, Piazzesi and Wei is the return on the equity market portfolio, which links the bond and equity markets. We are able to assess the importance of this link by comparing with a restricted expected-utility version of our model, in which the equity market variable disappears from the stochastic discount factor (SDF) (or pricing kernel or, in equilibrium, the intertemporal marginal rate of substitution).

A second contribution of the paper is to estimate the preference parameters and other crucial parameters for risk premiums. For their arbitrage-free model, Ang, Piazzesi, and Wei propose a sequential estimation strategy. They estimate the VAR parameters first and then they minimize the least-square distance between the observed market yields and the model-implied ones to recover the price-of-risk parameters. We follow a similar strategy and use our equilibrium model-implied yields to recover the preference parameters. We find that the estimated preference parameters are economically plausible: in the non-expected utility model, the CRRA is around 6 and the EIS is around 0.36. This adds new evidence coming from bond market data to the current debate in the long-run risk literature on whether the EIS parameter in recursive preferences is above or below one in value. ${ }^{5}$

By using the same VAR specification of the macroeconomic dynamics for both the equilibrium model and a benchmark arbitrage-free model, we are able to assess the relative contributions of the different modeling strategies for explaining stylized facts about risk premiums. Statistical tests of the expectations hypothesis conclude that bond risk premiums vary with the shape of the yield curve and that excess bond returns are indeed predictable. In particular,

\footnotetext{
${ }^{4}$ Gregory and Voss (1991) show that recursive preferences alone do not offer a solution to the bond premium puzzle, put forward by Backus, Gregory, and Zin (1989) and Donaldson, Johnsen, and Mehra (1990), which is that the representative agent model with power utility can account for the average risk premiums in holding-period bond returns and forward rates only with implausibly large values of the CRRA.

${ }^{5}$ Bansal and Yaron (2004) propose a long-run risk model to link economic uncertainty (consumption volatility) to asset prices. They reproduce some stylized facts only for values of the EIS greater than one.
} 
Cochrane and Piazzesi (2005) run predictive regressions of one-year excess returns on forward rates and find that the forecasts are highly significant. Cochrane and Piazzesi find a robust tentshaped pattern of slope coefficients for all maturities, with regression $R^{2}$ around $35 \%$. A major finding of our paper is that only the unrestricted version of our recursive utility equilibrium model can account for the violations of the expectations hypothesis documented by Cochrane and Piazzesi. ${ }^{6}$ The restricted expected-utility model and the reduced-form no-arbitrage model cannot account for the tent-shaped pattern and magnitude of coefficients from such predictive regressions of excess bond returns on forward rates. The non-expected utility model produces mean slope coefficients with the correct pattern across maturities and the actual coefficients found in the market data are also well covered by the respective confidence intervals. Further, the hump-shaped pattern in the term structure of unconditional volatilities of yields and yield changes is apparent in the recursive utility model but not in the restricted expected-utility model nor in the reduced-form no-arbitrage model. These findings support the hypothesis that equilibrium restrictions on risk-factor prices are essential to limit the variability of the SDF in order to reproduce the dynamics of bond risk premiums.

State-dependent preferences are commonly used in asset pricing. In Campbell and Cochrane (1999), risk aversion is varying over time with consumption surplus - a business cycle variable that measures the difference between current consumption and a benchmark consumption formed by habit. Recently, Campbell, Sunderam, and Viceira (2007) build a term structure model with time-varying risk aversion to characterize the changing correlation between inflation and real variables. Closer to our model, Melino and Yang (2003) generalize the standard recursive utility framework by allowing the representative agent to display state-dependent preferences and they show that such preferences can account for moments on equity and the risk-free rate. In order to explain the term structure of interest rates, however, we need only to allow for a time-varying subjective discount factor; CRRA and EIS remain time-invariant and can thus be deemed structural in our framework. The fact that we link the subjective discount factor to the short-term rate of interest as in Obstfeld (1990) is motivated by the central role played by the

\footnotetext{
${ }^{6}$ This violation of the expectations hypothesis extends the classic regressions of Fama and Bliss (1987) and Campbell and Shiller (1991). Fama and Bliss found that the spread between the $n$-year forward rate and the one-year yield predicts the one-year excess return of the $n$-year bond, with $R^{2}$ around $18 \%$. Campbell and Shiller found similar results forecasting yield changes with yield spreads. Cochrane and Piazzesi's findings substantially strengthen that evidence against the expectations hypothesis. Most important, they show that the same linear combination of forward rates predicts bond returns at all maturities, while Fama and Bliss and Campbell and Shiller relate each bond's expected excess return to a different forward spread or yield spread.
} 
short rate in the determination of bond prices. Indeed, most models in the bond pricing literature find a way to introduce the short-term rate in the SDF, including the popular bond pricing models of Vasicek (1977) and Cox, Ingersoll, and Ross (1985). ${ }^{7}$ In Campbell and Cochrane (1999), the subjective discount factor is chosen to match the risk-free rate with the average real return on Treasury bills. In the extension of their model by Wachter (2006) to explain the term structure of interest rates, the risk-free rate is made a linear function of the surplus and is therefore time-varying. That model could be reinterpreted as a habit model with a time-varying discount factor equal to a deterministic function the risk-free rate.

The recent paper by Piazzesi and Schneider (2006) is certainly the closest to ours. They also derive equilibrium yield curves under recursive preferences, but their approach differs in several respects. First, they express the SDF in terms of news about future consumption instead of a proxy return for the market portfolio as we do. They specify an exogenous state-space system for consumption growth and inflation and set values for the preference parameters in order to infer the equilibrium yields. Here we estimate the parameters of a VAR system including consumption growth and inflation and the preference parameters that rationalize the observed yields. In this sense, we follow more closely the no-arbitrage approach (e.g. Ang, Piazzesi, and Wei 2006), where prices of risk that rationalize the observed yields are extracted.

Several authors have shown the limitations of the traditional consumption-based capital asset pricing model (CCAPM) with expected utility in representing the historical co-movements of consumption and returns on bonds. Campbell (1986a) explores the relation between bond risk premiums and the time-series properties of consumption in a similar model. He shows that positive serial correlation in consumption growth imparts a downward slope to the yield curve. Boudoukh (1993) considers a model with power utility, but where consumption growth and inflation are determined by a heteroskedastic VAR. Boudoukh finds that heteroskedasticity in consumption growth and inflation is not strong enough to generate the predictability of excess bond returns found in the data. In Piazzesi (2005), affine general-equilibrium models are specified with preference shocks that are related to state variables, as in Campbell (1986b) and Bekaert and Grenadier (2003).

Wachter (2006) also proposes a consumption-based model of the term structure of interest rates, where nominal bonds depend on past consumption growth through habit, and on expected inflation. As already mentioned, this model is essentially the same as the habit model

\footnotetext{
${ }^{7}$ Those models are special cases of a larger class of affine term structure models (Duffie and Kan 1996 and Dai and Singleton 2000), in which the SDF is a function of multiple factors, in addition to the short rate.
} 
of Campbell and Cochrane (1999), but the sensitivity function of the surplus consumption to innovations in consumption is chosen so as to make the risk-free rate a linear function of the deviations of the surplus consumption from its mean. Moreover, Wachter calibrates her model so as to make the nominal risk-free rate in the model equal to the yield on a three-month bond at the mean value of surplus consumption.

The rest of this paper is organized as follows. Section 2 describes the equilibrium model with recursive utility preferences that is used to price bonds. We also specify the dynamics of the macroeconomic variables that influence the yields. Section 3 is dedicated to model estimation and evaluation. We specify the benchmark no-arbitrage model, the data sources, and the econometric methodology used to estimate the parameters and ultimately to compute the yields. We report the pricing errors for the various specifications as well as variance decompositions and out-of-sample forecasts. Section 4 presents the empirical implications for the term structure of volatilities and the analysis of risk premiums. Section 5 offers some concluding remarks.

\section{Equilibrium Model}

The recursive utility model suggested by Epstein and Zin (1989) and Weil (1989) allows for a constant Arrow-Pratt CRRA that can differ from the reciprocal of the EIS. In so doing, that framework provides a partial separation of attitudes toward risk from preferences over deterministic consumption paths. Melino and Yang (2003) generalize the standard recursive utility framework by allowing the representative agent to display state-dependent preferences and show that such preferences can account for moments on equity and the risk-free rate. In order to explain the term structure of interest rates, however, we need only to allow for a variable rate of time preference; CRRA and EIS remain time-invariant and can thus be deemed structural in our framework. As in the standard framework, we consider an infinitely lived representative agent who receives utility from the consumption of a single good. In any period $t$, current consumption is deterministic but future consumption is uncertain. The agent's lifetime utility is characterized by

$$
U_{t}=\left(C_{t}^{\rho}+\beta_{t} \mu_{t}^{\rho}\right)^{\frac{1}{\rho}}
$$

where $0<\beta_{t}$ is the time-varying subjective discount factor and $\mu_{t}=E_{t}\left[\widetilde{U}_{t+1}\right]$ is a certainty

equivalent of random future utility, $\widetilde{U}_{t+1}$, given the information available to the agent at time $t$. The way the agent forms the certainty equivalent of random future utility is based on risk preferences, which are assumed to be isoelastic; i.e., $\mu_{t}^{\alpha}=E_{t}\left[\widetilde{U}_{t+1}^{\alpha}\right]$. Melino and Yang show that, 
as in the standard recursive utility case, $\alpha \leq 1$ can be interpreted as a relative risk aversion parameter with the degree of risk aversion increasing as $\alpha$ falls ( $1-\alpha$ is the CRRA). The parameter $\rho$ can be interpreted as reflecting substitution, since $1 /(1-\rho)$ is the EIS.

The SDF used by the agent to discount future payoffs to determine current asset prices is expressed as

$$
m_{t+1}=\beta_{t}^{\gamma}\left(\frac{C_{t+1}}{C_{t}}\right)^{\gamma(\rho-1)}\left(R_{t+1}\right)^{\gamma-1},
$$

where $R_{t+1}$ is the one-period gross rate of return on the market portfolio and $\gamma=\alpha / \rho$. Equation (2) shows that the SDF is a geometric weighted average of the rate of growth of consumption and the rate of return on the market portfolio. Market prices can then be expressed by the expected-value relation

$$
p_{t}=E_{t}\left[m_{t+1} g_{t+1}\right]
$$

where $p_{t}$ is the asset price and $g_{t+1}$ is the asset's future payoff. Note that the quantity in (2) is a strictly positive random variable that must satisfy (3).

The basic asset pricing equation can also be written as $1=E_{t}\left[m_{t+1} r_{t+1}\right]$, where $r_{t+1}=$ $g_{t+1} / p_{t}$ defines gross returns. Gross returns can be defined either in nominal or real terms; correspondingly, the SDF must then be expressed in nominal or real terms. In nominal terms, the SDF in (2) becomes

$$
m_{t+1}^{\$}=\beta_{t}^{\gamma}\left(\frac{C_{t+1}}{C_{t}}\right)^{\gamma(\rho-1)}\left(R_{t+1}\right)^{\gamma-1}\left(\frac{P_{t+1}}{P_{t}}\right)^{-1}
$$

where $P_{t+1} / P_{t}$ is the gross rate of inflation between periods $t$ and $t+1 ; P_{t}$ is the nominal price index at time $t$. Let $r_{t}=\log R_{t}$ represent the logarithm of the return on the market portfolio, $\pi_{t}=\log P_{t} / P_{t-1}$ the rate of inflation, and $c_{t}=\log C_{t} / C_{t-1}$ the rate of consumption growth.

Preferences with time-varying rates of time preference were introduced by Uzawa (1968), and have been extended by Epstein $(1983,1987)$. Those preferences specify the subjective discount factor as a function of consumption, so that the marginal utility of consumption in a given period can vary with consumption in other periods. This type of preferences has been applied to problems in international trade by Calvo and Findlay (1978), Obstfeld (1981), Mendoza (1991), Uribe (1997), and Schmitt-Grohé (1998). A further study includes Bergman (1985), where the implications of such preferences for the CAPM are examined. Obstfeld (1990) presents a general class of recursive utility functions, where the rate of time preference is a function of the interest rate. In our nominal model, the subjective discount factor is linked to an exogenously 
determined risk-free rate of interest via the key restriction

$$
\gamma \log \beta_{t}=-y_{t}^{(1)}
$$

where $y_{t}^{(1)}$ is the log yield on a one-quarter bond; i.e., one period is a quarter in our discrete-time yield-curve model. Note that (5) implies that $\beta_{t}^{\gamma}$ takes values between zero and one, since it equals the price of the one-quarter bond. As in Obstfeld (1990), our model with a variable rate of time preference implies that consumption and asset prices depend on a short-term rate of interest. The restriction in (5) might give the impression that the model will admit arbitrage opportunities. We will see that the SDF in (4) with (5) coupled with an affine specification ensures that the resulting bond prices remain arbitrage-free.

Further, if not more important, the restriction in (5) is motivated by the central role played by the short-term rate of interest in the determination of bond prices. Indeed, the short rate is a fundamental building block for yields of other maturities, which are just risk-adjusted averages of expected future short rates. Typically, bond pricing models are formulated as affine functions of a number of state variables that capture the uncertainty present in the economy. When three latent factors are specified, they are often interpreted as the level, slope, and curvature of the yield curve, following Litterman and Scheinkman (1991). At a quarterly frequency, the first principal component of yields accounts for $97.2 \%$ of the variation of yields and that first principal component has a $-95.6 \%$ correlation with the short rate (Ang, Piazzesi, and Wei 2006). Obviously, a model misspecification of this quantity leads to considerable pricing errors. Therefore most models in the bond pricing literature find a way to introduce the short-term rate in the SDF. Two of the most popular bond pricing models are those by Vasicek (1977) and Cox, Ingersoll, and Ross (1985) (CIR). Each of these models has a single factor, typically associated with the short rate. For example, Bansal and Zhou (2002) introduce the short rate by assuming that the log return on the asset that delivers the consumption stream (in a standard consumption-based asset pricing model) follows a CIR process and by using the fact that the conditional mean of the SDF is equal to the price of the risk-free, one-period discount bond. The Vasicek and CIR models are special cases of a larger class of affine term structure models (Duffie and Kan 1996 and Dai and Singleton 2000). The SDF in these models is a function of multiple factors, in addition to the short rate. Ang, Piazzesi, and Wei (2006) use the short rate as a proxy for the latent level factor of the yield curve, which is then used with other observable factors to price bonds at longer maturities. Bekaert and Grenadier (2003) use moments of the nominal short rate to calibrate the moments of the latent level factor in various arbitrage-free and equilibrium models, while Wachter (2006) extends the external habit model of Campbell and 
Cochrane (1999) by making the interest rate a function of surplus consumption. The average level of the short interest rate in that model is set equal to its sample counterpart.

Following Ang, Piazzesi, and Wei (2006), our model is based entirely on observable factors, which we collect in a state vector $X_{t}$. Both macroeconomic variables and yield curve factors are included in the state vector. Ang, Piazzesi, and Wei argue that two yield curve factors are sufficient to model the dynamics of yields at the quarterly frequency. Following those authors, we use the short rate, $y_{t}^{(1)}$, to proxy for the level factor of the yield curve and the five-year term spread, $y_{t}^{(20)}-y_{t}^{(1)}$, to proxy for the slope factor of the yield curve. The term spread has a $-86.5 \%$ correlation with the second principal component of yields. Adding the second principal component brings the percentage of yield-curve variation to $99.7 \%$. Although the term structure factors can explain the yield curve, that does not necessarily mean that they can explain risk premiums. Indeed, we will see that the macroeconomic factors and the restricted way in which they enter the SDF play a key role in explaining violations of the expectations hypothesis.

The macroeconomic factors are collected along with two term structure factors in the state vector so that $X_{t}=\left(y_{t}^{(1)}, y_{t}^{(20)}-y_{t}^{(1)}, r_{t}, \pi_{t}, c_{t}\right)^{\prime}$. As in Ang, Piazzesi, and Wei (2006), the vector of state variables follows a first-order VAR process:

$$
X_{t}=\mu+\Phi X_{t-1}+\Sigma \varepsilon_{t}
$$

where the errors are normally distributed with mean zero and $E\left[\varepsilon_{t} \varepsilon_{t}^{\prime}\right]=\Sigma \Sigma^{\prime}$. Despite the apparent simplicity of (6), we will see that the resulting bond pricing model fits the data extremely well. The logarithm of the nominal SDF can then be written as

$$
\log m_{t+1}^{\$}=-y_{t}^{(1)}+J X_{t+1}
$$

where $J=(0,0, \gamma-1,-1, \alpha-\gamma)$. We will see that an affine structure ensures the identification of the corresponding equations in the state VAR process, even though the vector $J$ contains zeros.

The time- $t$ price of a nominal bond that pays one dollar at time $t+n$ is determined by the recursive relation

$$
P(t, n)=E_{t}\left[m_{t+1}^{\$} \times P(t+1, n-1)\right],
$$

with the terminal condition $P(t+n, 0)=1$. Note that when $n=1$, the SDF in (7) will satisfy the usual relationship

$$
r_{t}^{f}=1 / E_{t}\left[m_{t+1}^{\$}\right],
$$


where $r_{t}^{f}$ is the gross risk-free rate of interest. Bond prices are parameterized as exponential linear functions of the state vector so that

$$
P(t, n)=\exp \left(A(n)+B(n)^{\prime} \times X_{t}\right)
$$

for a scalar $A(n)$ and a $5 \times 1$ vector $B(n)$ of coefficients that are functions of the time-to-maturity $n$. Solutions for those coefficients are based on the assumption that $m_{t+1}^{\$} \times P(t+1, n-1)$ is conditionally log-normal and the associated moments:

$$
\begin{aligned}
E_{t}\left[\log m_{t+1}^{\$}\right] & =-y_{t}^{(1)}+J\left(\mu+\Phi X_{t}\right), \\
E_{t}[\log P(t+1, n-1)] & =A(n-1)+B(n-1)^{\prime} \times\left(\mu+\Phi X_{t}\right), \\
\operatorname{Var}_{t}\left[\log m_{t+1}^{\$}\right] & =J \Sigma \Sigma^{\prime} J^{\prime}, \\
\operatorname{Var}_{t}[\log P(t+1, n-1)] & =B(n-1)^{\prime} \times \Sigma \Sigma^{\prime} \times B(n-1), \\
\operatorname{Cov}_{t}\left[\log m_{t+1}^{\$}, \log P(t+1, n-1)\right] & =B(n-1)^{\prime} \times \Sigma \Sigma^{\prime} J^{\prime} .
\end{aligned}
$$

More precisely, bond prices are given by (8) with coefficients $A(n)$ and $B(n)^{\prime}$ determined by the backward recursions

$$
\begin{aligned}
A(n+1) & =A(n)+\left[J+B(n)^{\prime}\right] \mu+\frac{1}{2}\left[J+B(n)^{\prime}\right] \Sigma \Sigma^{\prime}\left[J^{\prime}+B(n)\right], \\
B(n+1)^{\prime} & =\left[J+B(n)^{\prime}\right] \Phi-e_{1},
\end{aligned}
$$

where $e_{1}=(1,0,0,0,0)$. The initial conditions are $A(1)=0$ and $B(1)^{\prime}=-e_{1}$. The difference equations in (9) that determine $A(n)$ and $B(n)^{\prime}$ are derived by induction, exactly as in Ang and Piazzesi (2003).

The inclusion of the two term structure factors $y_{t}^{(1)}$ and $y_{t}^{(20)}-y_{t}^{(1)}$ in the state vector implies that the model prices the one- and twenty-quarter bonds without error. The first set of these internal consistency constraints is given by the initial conditions for the recursive definitions of the coefficients $A(n)$ and $B(n)$. The second set of constraints is

$$
\begin{aligned}
A(20) & =0 \\
B(20)^{\prime} & =-20\left(e_{1}+e_{2}\right),
\end{aligned}
$$

where $e_{i}$ is a $5 \times 1$ vector of zeros with a 1 in the $i$ th element. These constraints ensure that the twenty-quarter yield is the sum of the first two factors in $X_{t}$. The other yields are then functions of $y_{t}^{(1)}$ and $y_{t}^{(20)}-y_{t}^{(1)}$ and the other factors included in $X_{t}$. The yields not included as factors are thus subject to a sampling error. 
The second equation of the backward recursions in (9) features the product $J \Phi$, which might give the impression that the short rate and the term spread cannot be identified via bond prices. The initial conditions, however, ensure the identification of the short-rate equation in the state VAR process. To see that the term spread is also identified, note that when the persistence matrix $\Phi$ admits an inverse, the factor loadings can be written as a forward recursion:

$$
B(n)^{\prime}=\left[B(n+1)^{\prime}+e_{1}\right] \Phi^{-1}-J
$$

with the terminal conditions in (10). This recursion is mathematically equivalent to the one in (9) and makes clear that the term-spread equation is statistically identified.

The bond pricing equation in (8), along with the coefficients in (9), provides a characterization of the entire yield curve. In particular, it describes the joint dynamics of bond yields of various maturities and the vector of state variables. The model-implied yield on a continuously compounded $n$-period zero-coupon bond, $Y(t, n)=-\log P(t, n) / n$, is an affine function of the state vector:

$$
Y(t, n)=-\frac{A(n)}{n}-\frac{B(n)^{\prime}}{n} X_{t}
$$

From the bond pricing equation, the time- $t$ model-implied forward rate which applies between times $t+n$ and $t+n+s(s \geq 1), F(t, n, s)=(\log P(t, n)-\log P(t, n+s)) / s$, can be computed as

$$
F(t, n, s)=-\frac{[A(n+s)-A(n)]}{s}-\frac{\left[B(n+s)^{\prime}-B(n)^{\prime}\right]}{s} X_{t},
$$

and the short rate expected to prevail at time $t+n$ is given by

$$
E_{t}\left[y_{t+n}^{(1)}\right]=e_{1}\left[\sum_{i=1}^{n} \Phi^{n-i} \mu+\Phi^{n} X_{t}\right]
$$

where $\Phi^{0}$ is set equal to the $5 \times 5$ identity matrix.

The expectations hypothesis is a restriction on the risk premium in the relationship

$$
F(t, n, 1)=E_{t}\left[y_{t+n}^{(1)}\right]+R P(t, n)
$$

where $R P(t, n)$ is the time- $t$ risk premium. From the difference equation in (9), we have $B(n+$ $1)^{\prime}-B(n)^{\prime}=\left(J-e_{1}\right) \Phi^{n}$. So the model-implied risk premium is

$$
R P(t, n)=-J \Phi^{n} X_{t}+\text { constant }
$$

The expression in (15) shows that in addition to the preference parameters in $J$, the persistence matrix $\Phi$ also plays a crucial role for the risk premiums. Indeed when $\Phi=0$, there is no 
systematic risk, the risk premium is constant, and the expectations hypothesis holds. In contrast, the risk premium is time varying whenever $\Phi \neq 0$.

With the restriction $\alpha=\rho$, the model reduces to an expected utility model albeit except for the time-varying subjective discount factor. The expected utility version implies a separable time-additive preference structure, since the short-term rate of interest is exogenous; i.e., the subjective discount factor does not depend on consumption choices. In that case, the CRRA is the reciprocal of the EIS and the return on the market portfolio plays no contemporaneous role in the SDF.

The appearance of the market return as a state variable in the non-expected utility specification implies that the model should also consistently price the market portfolio. This additional constraint imposes a very tight link between bond yields and equity returns. The model then fails to fit the data with any meaningful parameter values owing to the much greater time-varying volatility of equities relative to bonds; i.e, the model does not offer a solution to both the equity and bond premium puzzles, simultaneously. With this caveat in mind, the next section presents an empirical assessment of the equilibrium model and the role played by the macroeconomic factors in explaining bond risk premiums.

\section{Model Estimation and Evaluation}

\subsection{Benchmark model}

The described equilibrium model links the dynamics of the term structure of interest rates to macroeconomic variables. Ang and Piazzesi (2003) also establish such a link through a reducedform model of the term structure. For comparison, their approach is used here to derive a reduced-form bond pricing equation given the same specification of state variables used for the equilibrium-based model.

The approach assumes that the nominal SDF follows a conditionally log-normal process of the form

$$
\log m_{t+1}^{\$}=-y_{t}^{(1)}-\frac{1}{2} \lambda_{t}^{\prime} \lambda_{t}-\lambda_{t}^{\prime} \varepsilon_{t+1},
$$

where $\lambda_{t}$ are time-varying market prices of risk. The vector $\lambda_{t}$ is parametrized as an affine process:

$$
\lambda_{t}=\lambda_{0}+\lambda_{1} X_{t}
$$

so that $\lambda_{0}$ is a $5 \times 1$ vector and $\lambda_{1}$ is a $5 \times 5$ matrix. Equations (16) and (17) relate shocks in 
the state VAR process to the SDF and therefore determine how those factor shocks affect all yields. The implied no-arbitrage bond yields are given by

$$
Y^{n a}(t, n)=-\frac{A^{n a}(n)}{n}-\frac{B^{n a}(n)^{\prime}}{n} X_{t}
$$

where the coefficients $A^{n a}(n)$ and $B^{n a}(n)^{\prime}$ are defined recursively by

$$
\begin{aligned}
A^{n a}(n+1) & =A^{n a}(n)+B^{n a}(n)^{\prime} \times\left(\mu-\Sigma \lambda_{0}\right)+\frac{1}{2} B^{n a}(n)^{\prime} \times \Sigma \Sigma^{\prime} \times B^{n a}(n), \\
B^{n a}(n+1)^{\prime} & =B^{n a}(n)^{\prime} \times\left(\Phi-\Sigma \lambda_{1}\right)-e_{1},
\end{aligned}
$$

with $e_{1}=(1,0,0,0,0)$. As before, we have restrictions of the form $A^{n a}(1)=0, B^{n a}(1)^{\prime}=-e_{1}$ and $A^{n a}(20)=0, B^{n a}(20)^{\prime}=-20\left(e_{1}+e_{2}\right)$. See Ang and Piazzesi (2003) and Ang, Piazzesi, and Wei (2006) for additional details.

The definition of the SDF in (16) makes clear the role of $\lambda_{0}$ and $\lambda_{1}$ for risk premiums in the reduced-form model. When $\lambda_{0}=0$ and $\lambda_{1}=0$, there are no risk premiums and a local version of the pure expectations hypothesis holds. In this case, the price of an $n$-period bond is $P^{n a}(t, n)=E_{t}\left[\exp \left(-\sum_{i=1}^{n} y_{t+i}^{(1)}\right)\right]$, so that apart from some Jensen-inequality terms, long-term rates are simply the expected value of average future short-term rates. When $\lambda_{1}=0$, market prices of risk do not depend on $Y_{t}$ and the risk premium is constant.

\subsection{Data description}

The macroeconomic fundamentals VAR model is estimated using data on U.S. nominal interest rates, equities, inflation, and real consumption. Although the raw data are available at the monthly frequency, we follow Campbell and Viceira (2001) and Wachter (2006) and construct a quarterly data set in order to reduce the influence of higher-frequency noise in inflation and shortterm movements in interest rates. As Wachter states, higher-frequency interest-rate fluctuations would seem difficult to explain using an equilibrium model with macroeconomic variables. ${ }^{8}$

Real aggregate consumption is based on personal consumption expenditures on nondurables and services obtained from the Bureau of Economic Analysis. Per capita consumption is obtained by dividing the real aggregate consumption by the total population. The level of the market portfolio is proxied using a value-weighted index of stocks, including dividends, traded on the NYSE, AMEX, and NASDAQ markets obtained from the Center for Research in Security Prices (CRSP). For inflation, we use data on the Consumer Price Index (CPI) obtained from the Federal

\footnotetext{
${ }^{8}$ Another important consideration is the computational cost involved. Indeed, the depth of recursions when computing (9) and (19) with monthly data prohibits a thorough exploration of the parameter space.
} 
Reserve Bank of St. Louis. The level data on real per capita consumption, the stock index, and the CPI were aggregated up to the quarterly frequency by averaging the monthly observations. The return on the market portfolio, the rate of inflation, and the growth rate of consumption were then defined as the changes in the (log) values of the corresponding level data. The bond data consist of a set of monthly zero-coupon yields obtained from CRSP. These monthly yields were averaged to obtain quarterly yields on bonds with maturities of $1,2,4,8,12,16$, and 20 quarters. These data definitions ensure that the yields incorporate information about the rates of inflation, consumption growth, and market return throughout the quarter. The quarterly data set has 182 observations from 1959Q3 to 2004Q4.

Table 1 provides summary statistics of the yield data at the quarterly frequency. As usual, the yield curve slopes upward on average. Further, the standard deviation, skewness, and kurtosis tend to be higher for shorter bond maturities.

\subsection{Estimation methodology}

Following Ang, Piazzesi, and Wei (2006), we adopt a consistent two-step procedure to estimate the model parameters. For the reduced-form model, we estimate in a first step the VAR parameters $\mu, \Phi$, and $\Sigma$ by least squares. In the second step, we estimate the parameters that determine the market prices of risk $\left(\lambda_{0}\right.$ and $\left.\lambda_{1}\right)$ given the estimates of the VAR parameters from the first step. ${ }^{9}$ This is done by solving the non-linear least-squares problem:

$$
\min _{\left\{\lambda_{0}, \lambda_{1}\right\}} \sum_{T} \sum_{N}\left(y_{t}^{(n)}-Y^{n a}(t, n)\right)^{2}
$$

where $y_{t}^{(n)}$ is the market yield of an $n$-period bond at time $t$ and $Y^{n a}(t, n)$ is the corresponding model-implied yield; the first summation is over available time observations and the second summation is over the yields used to estimate the model. Minimization was done with the Nelder-Mead simplex algorithm, and once the optimum was found, the covariance matrix was estimated using numerical derivatives of the non-linear regression function with respect to the vector of parameters. ${ }^{10}$

\footnotetext{
${ }^{9}$ Of course, this step-by-step estimation methodology does not deliver the most statistically efficient estimates. On the other hand, its computational simplicity is a considerable advantage, especially when the models need to be updated on a regular basis.

${ }^{10}$ As a further check, we also computed bootstrap standard errors by recursively generating data according to the VAR specification, then generating yield data from the bond pricing formulas, and finally estimating the model parameters using the simulated data. A bootstrap distribution was generated from 1000 replications
} 
A similar two-step procedure is used to estimate the parameters of the equilibrium-based model, thereby ensuring a meaningful comparison across specifications. As the expression in (15) shows, the two preference parameters $(\gamma$ and $\alpha)$ and the $5 \times 5$ matrix $\Phi$ play a crucial role for the equilibrium risk premiums. To emphasize this point, note that if the data were actually generated according to the local expectations hypothesis, we would expect to find statistically insignificant values of $\lambda_{0}$ and $\lambda_{1}$ in the reduced-form model. On the other hand, we would expect to find insignificant values of $\Phi$ if the equilibrium-based model was taken to the yields data under the expectations hypothesis. For this reason, estimation of the equilibrium-based model takes only the least-squares estimate of $\mu$ and $\Sigma$ as given. The second step solves the non-linear least-squares problem with respect to the $\mathrm{CRRA}=1-\alpha$, the $\mathrm{EIS}=1 /(1-\rho)$, where $\rho=\alpha / \gamma$, and the persistence matrix $\Phi$, subject to the constraints in (10). So as in the case of the reduced-form model, we let the bond market data tell us whether risk premiums in the equilibrium model are time-varying.

The estimation of the equilibrium-based model and the reduced-form model involves about the same number of parameters in each case. It is also important to note that the two specifications are not nested. This means that we would not expect the reduced-form model to necessarily provide a better fit to the data.

\subsection{Estimation results}

Estimation results for the equilibrium model are reported in Table 2, along with $95 \%$ confidence intervals for each parameter. The table reports results for both the non-expected utility case and the expected utility case where the CRRA is the reciprocal of the EIS. The point estimate for the CRRA in the unrestricted case is around 6, and is estimated quite precisely as seen from the narrow confidence interval. This value is roughly consistent with the GMM results of Epstein and Zin (1991), who found a low value of the CRRA close to one. Schwartz and Torous (1999) argue that empirical tests have difficulty disentangling the EIS from the CRRA because the data that are typically used, which includes returns on stocks and short-term bonds, do not capture the time dimension needed to accurately measure the EIS. Schwartz and Torous explain that the EIS deals with the willingness of investors to allocate consumption over time, and thus term structure data can better capture this temporal effect. Schwartz and Torous find a GMM point estimate for the CRRA of 5.65 in the recursive utility framework. These values of the

of this (numerically intensive) procedure. The bootstrap confidence intervals were similar to those reported in Tables 2 and 4. 
CRRA around 6 fall in the range obtained by Malloy, Moskowitz, and Vissing-Jørgensen (2006) also in the recursive utility framework, but from micro-level household consumption data. These authors show that the CRRA implied by the cross-sectional reward for long-run consumption risk of stockholders is around 8, and as low as 5 for the wealthiest third of stockholders with the largest equity holdings.

Table 2 shows that the EIS is also estimated quite precisely, with a point estimate of 0.359 . That value is also consistent with the findings of Epstein and Zin (1991) who found the EIS to be statistically less than 1. Schwartz and Torous (1999) report a point estimate of 0.226 for the EIS. Their results corroborate the work of Hall (1988) and Campbell (1999), who conclude that the EIS is small and positive and statistically different from zero. It is interesting to note that, while the non-expected and expected utility cases have statistically different estimates of the CRRA, they nonetheless have similar estimates of the EIS. Figure 1 shows the subjective discount factor, $\beta_{t}$, implied by the non-expected utility model. The plot corresponds to the price of the one-quarter bond scaled by the estimated value of $\gamma$; see equation (5).

Looking at the estimates of $\Phi$ in the non-expected utility case, each of the state variables appears statistically significant as some element. The short rate and the term spread appear as their own significant predictors, which is not surprising given the persistent nature of those variables. The term spread, inflation, and consumption growth appear to be significant predictors of the market return in the third row of $\Phi$. Inflation, in the fourth row, is explained by its own lag and consumption growth. Finally, consumption growth is explained by its own lag.

As in Piazzesi and Schneider (2006), inflation brings bad news for future consumption since inflation is negatively correlated with future consumption growth. However, the implied correlation between consumption growth and lagged consumption growth is negative (-0.409) while it is positive historically in the data (0.208; see Table 3$)$. The interpretation of this result is challenging. Reasons could be that the implied dynamics are for a representative investor since substantial differences have been put forward between the consumption of stockholders and non-stockholders. ${ }^{11}$ An intertemporal substitution effect could explain the negative consumption growth autocorrelation. Evidence of such forward-looking consumption-savings decisions by households is found in Nalewaik (2006). Using twenty years of microeconomic data from the

\footnotetext{
${ }^{11}$ Mankiw and Zeldes (1991) proposed the idea that limited participation in asset markets matters for the relation between consumption and asset returns. They found large differences in relative risk aversion estimates between the stockholders and the non-stockholders, implied by different consumption processes for these two groups. Vissing-Jørgensen (2002) shows that estimates of the EIS also differ significantly between asset holders and non-asset holders.
} 
Consumer Expenditure Surveys, he finds a large negative first-order autocorrelation for consumption growth. ${ }^{12}$ Another reason could be a misspecification of the consumption process. The representative investor may fear a regime with a very negative consumption growth that translates into a negative estimate for the coefficient of lagged consumption in the consumption growth equation because this bad regime is not accounted for in the model. Garcia, Luger, and Renault (2003) find evidence of such regime effects in the context of an equilibrium-based option pricing model. Interestingly, the signs and magnitudes of the coefficients in the market return equation are similar in the implied $\Phi$ matrix in Table 2 and the matrix estimated without the bond data in Table 3. That is also the case for the yield spread. The signs are also preserved in the short rate equation for inflation and consumption growth.

The estimate of $\Phi$ under expected utility exhibits a very different pattern. In that case, the only significant elements are the short rate and the term spread as their own predictors. Lagged values of the inflation rate, the return on the market portfolio, and consumption growth are nowhere significant. The fact that consumption makes no significant contribution provides yet more evidence against the consumption-based asset pricing model with power utility. It is interesting to note that the point estimates coefficients of lagged inflation and lagged consumption growth in both the inflation and the consumption equations are not different in the non-expected utility and the expected utility panels.

Table 4 reports the parameter estimates for the reduced-form model. The reported confidence intervals reveal that many of the parameter estimates have large standard errors, as is common in reduced-form factor models of the term structure. The market return is the only variable that appears significant in the average market price of risk, $\lambda_{0}$. This result is interesting since Ang and Piazzesi (2006) find that such unconditional means are hard to pin down in small samples owing to the persistent nature of bond yields. On the other hand, each of the state variables plays some significant role in determining the time variation of market prices of risk. The significance of every element in the third column of $\lambda_{1}$ corresponding to the market return is worth noticing.

Table 5 reports summary statistics of the in-sample absolute pricing errors (in basis points) for the various specifications. It is immediately clear that relaxing the expected utility constraint improves the fit of the equilibrium model. This result confirms that the market return plays a

\footnotetext{
${ }^{12}$ It is interesting to note that Otrok, Ravikumar, and Whiteman (2002) find that the autocorrelation of annual consumption growth is -0.26 over the period 1890-1930, and Chapman (2002) finds the autocorrelation to be -0.16 over the period 1890-1948. The consumption process used by Mehra and Prescott (1985) has an autocorrelation of -0.14 . They base their parameter values on annual data covering the period 1889-1978.
} 
relatively important contemporaneous role in the pricing of bonds. The unrestricted equilibrium model fares well against the reduced-form model, as seen from the small differences in pricing errors. The maximal pricing error in Table 5 is only about 140 basis points, which occurs under the restricted equilibrium model with 4-quarter bonds. Despite the relative differences across models, the pricing errors in Table 5 show that the three specifications fit very well by any standard.

\subsection{Variance decompositions}

The model-implied yields in equations (12) and (18) show that the effects of each state variable on the yield curve are determined by the factor loadings $B(n)$ and $B^{n a}(n)$, respectively. Further, those equations identify the error in forecasting yields with the error in forecasting the VAR. Following Ang and Piazzesi (2003), the proportion of the forecast error attributable to each state variable can be computed from a standard variance decomposition of the VAR. Tables 6-8 show the relative contributions of each state variable to the mean squared forecast errors of bond yields, for various forecast horizons. Note that even though the market return plays no contemporaneous role in the SDF under expected utility, it is still a predictor of the other state variables in the VAR and hence still makes a contribution in forecasting future bond yields.

It is immediately clear upon comparing Tables 6-8 that the state variables make similar contributions in forecasting future bond yields across the three specifications. The contribution of the short rate decreases with both the maturity and the forecast horizon. On the other hand, the spread's contribution increases with the bond's maturity, but tends to decrease with the forecast horizon as the maturity increases. The contribution of the two yield curve factors across maturities follows by construction. Recall that the three models are constrained to price the shortest and the longest maturity bonds without error in-sample. The proportions of unconditional variance accounted for by the short rate and the term spread range from around $80 \%$ and $1.3 \%$, for the 2-quarter yield, to about $70 \%$ and $10 \%$, for the 16 -quarter yield, respectively.

The proportions of forecast variance explained by the market return, inflation, and consumption exhibit interesting patterns. The market return's contribution is about $2.5 \%$ across both the bond maturity and the forecast horizon. The contribution by the rate of inflation is increasing with the forecast horizon, and about constant across bond maturities. That proportion increases from about $2 \%$ to $10 \%$ as the forecast horizon increases from 4 quarters to very long horizons. The effect of consumption growth is also increasing in the forecast horizon, and slightly 
decreasing in bond maturity. The long-run contribution of consumption growth in forecasting bond yields is about $7.5 \%$. It is interesting to note that the overall proportion of unconditional variance accounted for by the term structure factors is about $80 \%$ for all bond maturities, and the remaining $20 \%$ is accounted for by the market return, inflation, and consumption.

\subsection{Out-of-sample forecasts}

Duffee (2002) shows that traditional affine term structure models produce forecasts that are typically worse than forecasts produced by simply assuming that future yields are equal to current yields. ${ }^{13}$ Duffee explains that the poor forecasting performance of those traditional models is due to the fact that the implied compensation for risk is a multiple of the variance of the state vector. This tight link makes it difficult to replicate some stylized facts of historical excess bond returns. Duffee concludes that for the purpose of forecasting, traditional affine term structure models are largely useless. Ang and Piazzesi (2003) remark that market prices of risk that are affine functions of both macroeconomic and latent factors, which were not considered by Duffee (2002), seem to improve the forecasts. Ang and Piazzesi conclude that adding macro factors to a given number of latent factors in an affine term structure model results in better forecasts, even outperforming the random walk model.

The equilibrium and reduced-form models, based entirely on observable factors, are compared to the benchmark random walk model in terms of their one-quarter-ahead predictions. For each quarter $t$, we estimate the VAR model and the term-structure models using data up to and including quarter $t$, and then forecast the next quarter's yield curve using the VAR's forecasts for period $t+1$. Hence, we use only information available in period $t$ when forming the forecasts for period $t+1$. The forecasts from the benchmark random walk model are produced by simply assuming that future yields are equal to current yields. Given that we need at least 30 observations to estimate the reduced-form model, prediction abilities are compared over the period 1967Q1-2004Q4, resulting in 152 one-quarter-ahead forecasts. ${ }^{14}$

Table 9 reports summary statistics of the one-quarter-ahead absolute forecasts errors (in basis points). The first panel shows the results for the benchmark random walk model. The next two panels show the results for the non-expected and expected utility equilibrium models,

\footnotetext{
${ }^{13}$ See Egorov, Hong, and Li (2006) for related evidence.

${ }^{14} \mathrm{We}$ also repeated the forecast comparison starting at the sample mid-point to see if there were any effects from the choice of the initial estimation window. The results based on the resulting 91 observations were qualitatively similar to those reported in Table 9.
} 
respectively. The last panel shows the results for the reduced-form model. Note that, by construction, both versions of the equilibrium model and the reduced-form model have identical predictive abilities for 1 - and 20-quarter yields.

As in Ang and Piazzesi (2003), we also find that the three term-structure models slightly outperform the random walk model in terms of mean absolute errors. There are also some noticeable differences in terms of the other moments. In particular, the maximum absolute forecast errors from the term-structure models tend to be smaller than those from the random walk. Further, among the term-structure models, the maximum absolute forecast errors from the non-expected utility model are smaller than those from the other models for maturities of 4 , 8,12 , and 16 quarters. The fact that the three term-structure models only have slight differences when compared in terms of their predictive ability is perhaps not surprising given their similar variance decompositions. ${ }^{15}$

\section{Empirical Implications}

\subsection{Volatilities of Yields and Yield Changes}

Litterman, Scheinkman, and Weiss (1991) document a hump-shaped pattern in the term structure of unconditional volatilities of yields and yield changes. The top panel of Table 10 shows the volatilities of the actual market yields across maturities. Here the hump occurs at a maturity of two quarters: volatility is relatively lower for one-quarter bonds, peaks for two-quarter bonds, and then decreases monotonically as the maturity increases from four to twenty quarters. A similar pattern occurs in the term structure of unconditional volatilities of yield changes, shown in the top panel of Table 11.

Can any of the three model specifications reproduce the term structure of volatilities? To answer this question, we generated 1000 samples of artificial yields for each maturity of the same length as the actual data, under each model specification. This involved using the OLS estimates to recursively generate data for the state variables according to the VAR specification and then feeding those data into the bond-pricing formulas, evaluated at the point estimates in Tables 2 and 4, to generate the yields data.

The volatilities of the simulated yields and yield changes are reported in the bottom panels of Tables 10 and 11, respectively. The reported statistics are the mean values across the 1000

\footnotetext{
${ }^{15}$ The out-of-sample forecast comparison was also extended to a four-quarter horizon. The relative differences across the three models were similar to those at the one-quarter horizon.
} 
replications, along with asymmetric 95\% confidence intervals constructed from the quantiles of the simulated distributions. For both yields and yield changes, the non-expected utility model successfully reproduces the hump-shaped pattern of volatilities across bond maturities. On the contrary, the expected utility and the reduced-form models do not reproduce the hump. Indeed, Tables 10 and 11 show a strictly decreasing term structure of volatilities for those two specifications.

\subsection{Violations of the Expectations Hypothesis}

\section{Campbell-Shiller Regressions}

According to the expectations hypothesis of the term structure of interest rates, long-term yields are the average of expected future short yields over the holding period of the long-term asset, plus a constant risk premium. This implies that current spreads between yields of different maturities predict future yield changes. Campbell and Shiller (1991) consider predictive regressions of the form

$$
y_{t+1}^{(n-1)}-y_{t}^{(n)}=\beta_{0}^{(n)}+\beta_{1}^{(n)} \frac{1}{n-1}\left(y_{t}^{(n)}-y_{t}^{(1)}\right)+\varepsilon_{t+1}^{(n)},
$$

which should produce a slope coefficient of 1 under the expectations hypothesis. Campbell and Shiller find that the slope coefficient is less than 1 and decreasing in $n .{ }^{16}$ Bansal and Zhou (2002) show that this predictability evidence can be explained by a term structure model, where the short rate and the market prices of risks are subject to regime shifts. More generally, Dai and Singleton (2002) and Duffee (2002) show that the Campbell-Shiller findings can be explained by reduced-form term structure models, provided that the market prices of risk take some flexible form so that the expected excess bond returns are positively correlated with the yield spread. Wachter (2006) shows that a consumption-based model of the term structure with market prices of risk generated by external habit can also explain the Campbell-Shiller findings. It should be noted that Wachter calibrates her model to the data.

The question we ask here is whether any of the general-purpose term structure models we consider can generate the required risk premiums for the specific set of parameter values that correctly fit the data. Table 12 shows the results for the regression in (21) with $n=$

\footnotetext{
${ }^{16}$ The observed violations of the expectations hypothesis could also be the result of monetary policies that adjust short rates in response to the slope of the yield curve (see McCallum 1994, Kugler 1997, and Gallmeyer, Hollifield, and Zin 2005).
} 
4, 8, 12, 16, 20. ${ }^{17}$ The top panel shows the slope coefficients and $R^{2}$ 's found in the actual data. As in previous studies, the slope coefficients are negative and decreasing with maturity.

The three lower panels of Table 12 show how closely the three models can mimic the pattern of slope coefficients. Following Bansal and Zhou (2002) and Wachter (2006), we generated 1000 samples of artificial yields, as described above for the term structure of volatilities. For each simulated sample, we ran the regression in (21) and computed the $R^{2}$. The three lower panels of Table 12 report the mean slope coefficients along with asymmetric $95 \%$ confidence intervals. The non-expected utility model produces mean slope coefficients with the downward pattern across maturity and the actual coefficients are well covered by the respective confidence intervals. In the expected utility case, however, the mean slope coefficients do not decrease monotonically with $n$, although the actual coefficients are covered by the respective confidence intervals. Perhaps a more serious problem revealed by Table 12 is the slope coefficient associated with $n=4$ in the reduced-form model (first column, bottom panel). In that case, the mean slope coefficient is positive and the actual slope coefficient of -0.603 is only marginally covered by the confidence interval $[-0.675,1.747]$. This indicates that there might be a deeper problem with the implied risk premiums. We examine this further in predictive regressions of excess bond returns using forward rates.

\section{Cochrane-Piazzesi Regressions}

Another way to state the expectations hypothesis of the term structure of interest rates is that holding-period excess returns should not be predictable. Cochrane and Piazzesi (2005) consider the predictive regression of 4-quarter excess bond returns on the initial yield and forward rates:

$$
r x_{t+4}^{(n)}=\beta_{0}^{(n)}+\beta_{1}^{(n)} y_{t}^{(4)}+\sum_{i=2}^{5} \beta_{i}^{(n)} f_{t}^{(4 i)}+\varepsilon_{t+4}^{(n)}, \quad n=8,12,16, \text { and } 20,
$$

where $r x_{t+4}^{(n)}=p_{t+4}^{(n-4)}-p_{t}^{n}-y_{t}^{(4)}$ is the return (in excess of the 4-quarter bond yield) from buying an $n$-quarter bond at time $t$ and selling it as an $(n-4)$-quarter bond at time $t+4$, and $f_{t}^{n}=p_{t}^{(n-4)}-p_{t}^{(n)}$ is the forward rate for loans between time $t+n-4$ and $t+n ; p_{t}^{n}$ is the log price of an $n$-year bond at time $t$. Note that time increments are in years. Cochrane and Piazzesi find a robust tent-shaped pattern of slope coefficients for all maturities, with regression $R^{2}$ values around 35\%. This violation of the expectations hypothesis extends the classic regressions of Fama and Bliss (1987) and Campbell and Shiller (1991). Fama and Bliss found that the spread

\footnotetext{
${ }^{17}$ As usually done, the change $y_{t+1}^{(n)}-y_{t}^{(n)}$ is used instead of $y_{t+1}^{(n-1)}-y_{t}^{(n)}$, since $y_{t+1}^{(n-1)}$ is not available. Bekaert, Hodrick, and Marshall (1997) discuss the effects of this approximation.
} 
between the $n$-year forward rate and the one-year yield predicts the one-year excess return of the $n$-year bond, with $R^{2}$ about $18 \%$. As mentioned above, Campbell and Shiller found similar results forecasting yield changes with yield spreads. Cochrane and Piazzesi's findings substantially strengthen that evidence against the expectations hypothesis. In particular, they show that the same linear combination of forward rates - the regressors in (22) - predicts bond returns at all maturities, while Fama and Bliss and Campbell and Shiller relate each bond's expected excess return to a different forward spread or yield spread.

The size of the predictability and nature of projection coefficients in regressions like (22) is quite puzzling and, as Bansal, Tauchen, and Zhou (2004) state, "constitutes a serious challenge to term structure models." Bansal, Tauchen, and Zhou account for the predictability evidence from the perspective of latent factor term structure models. They show that the regime-switching model of Bansal and Zhou (2002) can empirically account for these challenging features of the data, while affine specifications cannot. In this section, we ask whether the risk premiums generated by our model (based on observable factors) can also account for the tent-shaped predictability pattern. To preview the results, it is only the non-expected utility model that can do so. Both the expected utility version of the equilibrium model and the reduced-form model fail to account for these important features. An important note is that the question is not whether one can construct market prices of risk that generate the return regressions in an affine model. Cochrane and Piazzesi (2005) show exactly how that can be done. As with the Campbell-Shiller regressions, the question we ask is whether any of the considered term structure models can generate the required risk premiums given the specific set of parameter values that correctly fit the data.

Estimation results for the regressions in (22) are reported in the top panel of Table 13. Consistent with the findings of Bansal, Tauchen, and Zhou (2004), we also found that the use of the five forward rates in (22) creates a near-perfect collinearity problem in our data set and, therefore, we concentrate on the regressions with $y_{t}^{(4)}, f_{t}^{(12)}$, and $f_{t}^{(20)}$ as regressors. The tentshaped finding of Cochrane and Piazzesi (2005) is apparent in the upper left plot of Figure 2, which plots the estimated regression coefficients. The regression $R^{2}$ reported in Table 13 further confirm their findings. The table shows that when the 8-quarter excess return is the regressand, the $R^{2}$ is around $34 \%$, and that value reaches nearly $38 \%$ when the 16 -quarter excess return appears as regressand.

The three lower panels of Table 13 show how closely the three models can mimic the tentshaped pattern of regression coefficients. Following Bansal, Tauchen, and Zhou (2004), we 
generated 1000 samples of the same length as the actual data for each model. As with the Campbell-Shiller regressions, this involved using the OLS estimates to recursively generate data for the state variables according to the VAR specification and then feeding those data into the bond-pricing formulas, evaluated at the point estimates in Tables 2 and 4, to generate the yields data. For each simulated sample, we ran the regression in (22) and computed the $R^{2}$. The three lower panels of Table 13 report the mean regression coefficients along with asymmetric 95\% confidence intervals. The upper right, lower left, and lower right plots of Figure 2 show the mean regression coefficients for the non-expected utility model, the expected utility model, and the reduced-form model, respectively. From those plots, it is immediately clear that only the non-expected utility model can empirically account for the tent-shaped pattern of coefficients from predictive regressions of excess bond returns on forward rates. The lower left plot of Figure 2 shows that the expected utility model fails to capture the predictability of the 3- and 5-year forward rate for all excess returns. As the lower right plot of Figure 2 shows, the reduced-form model fails even more so at capturing those predictability components. These shortcomings are further confirmed even when sampling error is accounted for. The confidence intervals in Table 13 show more formally the correspondence between the non-expected utility model and the actual data. In that case, all the actual coefficients are covered by the respective confidence intervals. On the contrary, the confidence intervals for both the expected utility model and the reduced-form model fail to cover several of the actual coefficients. In particular, all the coefficients associated with the 3 - and 5-year forward rates $\left(\beta_{3}^{(n)}\right.$ and $\left.\beta_{5}^{(n)}\right)$ are not covered by the respective confidence intervals derived under those two specifications.

The predictability results presented here can be related to those obtained by Bansal, Tauchen, and Zhou (2004) with term structure models based on latent factors. Those authors show that their preferred two-factor regime-switching specification captures business cycle movements between economic expansions and recessions, and that these transitions affect the term structure of interest rates. A recession usually means a significant decline in economic activity spread across the economy, lasting more than a few months, normally visible in real GDP. It is therefore not surprising that our equilibrium model featuring inflation and consumption - an important component of GDP — also justifies the size and nature of bond return predictability. What is more intriguing are the contrasts between the non-expected utility model and its restricted expected utility version and the reduced-form model. 


\subsection{Key Differences}

Why are the implied risk premiums so different? A comparison of the coefficients in (9) with those in (19) provides some hints. Aside from the presence of the vector $J$ in (9), the most notable difference between the two specifications is that the reduced-form model has $\mu-\Sigma \lambda_{0}$ and $\Phi-\Sigma \lambda_{1}$ in (19) instead of just $\mu$ and $\Phi$, respectively, in (9). This means that the effects of $\mu$ and $\Phi$ on bond yields cannot be disentangled from that of $\Sigma$. Figure 3 plots the intercept and factor loadings for maturities ranging from 1 to 20 quarters, where the solid lines correspond to the non-expected utility model, the dashed lines to the expected utility model, and the dotted lines to the reduced-form model. By construction, the intercept and factor loadings are identical in value at the beginning and end points. Both the short rate and the term spread load in similar fashions across the three specifications. Using the non-expected utility model as a benchmark for comparisons, we see that the tight link between $\mu$ and $\Phi$ and $\Sigma$ in the reduced-form specification leads to marked differences for the intercept terms (upper left plot), the market return loadings (middle right plot), the inflation loadings (lower left plot), and the consumption loadings (lower right plot). In those cases, we see a build-up effect as $n$ increases. Consider next the expected and non-expected utility models. The obvious difference is that the return on the market portfolio plays no contemporaneous role in the SDF under the expected utility specification. That expected utility restriction appears most noticeably in terms of the consumption loadings, especially for longer bond maturities (lower right plot).

Another related and important difference between the non-expected utility model and the reduced-form one can be seen from an examination of the innovations to their respective (log) SDFs, $\log m_{t+1}^{\$}-E_{t}\left[\log m_{t+1}^{\$}\right]$. The time series of implied innovations for the non-expected utility model are shown in the top plot of Figure 4 and those for the reduced-form model are shown in the middle plot of that Figure; the two plots are shown on the same scale. A striking result is the difference between the volatilities of the innovations. Indeed, the reduced-form SDF innovations appear far more volatile than those of the non-expected utility model. This clearly illustrates why the parameter estimates for the reduced-form model (in Table 4) have large standard errors. It also explains the behavior of the reduced-form factor loadings.

\section{Reconciling the differences}

The coefficients of the predictive regression in (22) are further analyzed by decomposing their

matrix form $\hat{\beta}^{(n)}=\left(X^{\prime} X\right)^{-1} X^{\prime} Y^{(n)}, n=8,12,16$, and 20. Table 15 shows the mean values of the matrix $\left(X^{\prime} X\right)^{-1}$ and the vectors $X^{\prime} Y^{(n)}$ across the 1000 bootstrap replications of the non- 
expected utility model and the reduced-form model. Using the non-expected utility model as the benchmark for comparison, we see that the reduced-form model generates initial yields $y_{t}^{(4)}$ and forward rates $f_{t}^{12}, f_{t}^{20}$ that are too volatile so that the associated $\left(X^{\prime} X\right)^{-1}$ matrix is too "small." This is readily seen in the lower right plot of Figure 2, where the 5-year coefficients are compressed around zero.

Recall that the reduced-form model is estimated following a two-step procedure as in Ang, Piazzesi, and Wei (2006); i.e., the $\lambda$ parameters that determine the market prices of risk are estimated conditional on the first-step VAR parameters. As a check on this constraint, we reestimated the $\lambda$ parameters conditional on the matrix $\Phi$ estimated from the non-expected utility model, reported in Table 2. Table 14 shows the parameter estimates of this modified reduced-form model. Compared to the original results in Table 4, the estimated $\lambda$ 's and their associated standard errors are seen to change quite dramatically. In most cases, the standard errors are smaller resulting in tighter confidence intervals. The bottom plot of Figure 4 shows the time series of innovations to the SDF of the modified reduced-form model. Relative to the pattern in the middle plot of that Figure for the original reduced-form SDF, the modification achieves a remarkable reduction in overall volatility.

The efficiency gains of the modified reduced-form model are apparent in the decomposition of the predictability coefficients, shown in the bottom portion of Table 15. The associated $\left(X^{\prime} X\right)^{-1}$ matrix is now much closer to that of the non-expected utility model and indeed, as Figure 5 shows, the modified reduced-form gets much closer to producing the tent-like pattern of predictability regression coefficients. These results are perhaps not surprising since the conditioning values of $\Phi$, which affect the second-step $\lambda$ 's, are precisely those that rationalize the risk premiums in the equilibrium model.

\section{Conclusion}

We have proposed an equilibrium model of the term structure of interest rates that can account for several stylized facts. In particular, this state-dependent recursive utility model can empirically account for the tent-shaped pattern and magnitude of coefficients from predictive regressions of excess bond returns on forward rates - documented by Cochrane and Piazzesi (2005). This is an important result since the equilibrium model ties the predictable variation in excess bond returns to underlying macroeconomic fundamentals and captures well the important features of bond risk premiums with economically plausible values for the structural preference 
parameters. The results emphasize the importance of both non-expected utility preferences and the variable rate of time preference for explaining violations of the expectations hypothesis.

Our findings point to the fact that arbitrage-free models with similar dynamics for the economic drivers produce stochastic discount factors that are too volatile and therefore cannot explain as well bond risk premiums. They fail to account for the constraints that investors' preferences may impose between the prices-of-risk factors. Our main contribution is to show that these constraints matter empirically.

Our empirical assessment reveals also that the equilibrium model fits the term structure of interest rates as well as the arbitrage-free model. Variance decompositions show that the state variables make very similar contributions in forecasting future bond yields across the three specifications. A noteworthy result is that the overall proportion of unconditional variance accounted for by the two term structure factors is about $80 \%$ for all bond maturities and the remaining $20 \%$ is accounted for by the return on the market portfolio, the rate of inflation, and the rate of consumption growth. An out-of-sample forecast exercise shows that both termstructure models have only slight differences when compared in terms of their predictive abilities. However, the recursive utility equilibrium model seems to reproduce better the hump-shaped pattern in the term structure of unconditional volatilities of yields and yield changes. 


\section{References}

Ang, A., S. Dong, and M. Piazzesi. 2004. "No-Arbitrage Taylor Rules." Columbia University Manuscript.

Ang, A. and M. Piazzesi. 2003. "A No-Arbitrage Vector Autoregression of Term Structure Dynamics with Macroeconomic and Latent Variables." Journal of Monetary Economics 50: $745-87$.

Ang, A., M. Piazzesi, and M. Wei. 2006. "What Does the Yield Curve Tell Us about GDP Growth?" Journal of Econometrics 131: 359-403.

Backus, D.K., A.W. Gregory, and S.E. Zin. 1989. "Risk Premiums in the Term Structure: Evidence from Artificial Economies." Journal of Monetary Economics 24: 371-399.

Bansal, R., G. Tauchen, and H. Zhou. 2004. "Regime Shifts, Risk Premiums in the Term Structure, and the Business Cycle." Journal of Business and Economic Statistics 22: 396-409.

Bansal, R. and A. Yaron. 2004. "Risks for the Long Run: A Potential Resolution of Asset Pricing Puzzles." Journal of Finance 59: 1481-1509.

Bansal, R. and H. Zhou. 2002. "Term Structure of Interest Rates with Regime Shifts." Journal of Finance 57: 1997-2043.

Bekaert, G., S. Cho, and A. Moreno. 2003. "New-Keynesian Macroeconomics and the Term Structure." Columbia University Working Paper.

Bekaert, G. and S. Grenadier. 2003. "Stock and Bond Pricing in an Affine Economy." Columbia University Working Paper.

Bekaert, G., R. Hodrick, and D. Marshall. 1997. "On Biases in Tests of the Expectations Hypothesis of the Term Structure of Interest Rates." Journal of Financial Economics 44: 309-348.

Bergman, Y.Z. 1985. "Time Preference and Capital Asset Pricing Models." Journal of Financial Economics 14: 145-159.

Boudoukh, J. 1993. "An Equilibrium Model of Nominal Bond Prices with Inflation-Output Correlation and Stochastic Volatility." Journal of Money, Credit, and Banking 25: 636665 .

Calvo, G.A. and R. Findlay. 1978. "On the Optimal Acquisition of Foreign Capital through Investment of Oil Export Revenues." Journal of International Economics 8: 513-524. 
Campbell, J.Y. 1986a. "Bond and Stock Returns in a Simple Exchange Model." Quarterly Journal of Economics 101: 785-804.

Campbell, J. 1986b. "A Defense of the Traditional Hypotheses about the Term Structure of Interest Rates." Journal of Finance 41: 183-93.

Campbell, J.Y. 1999. "Asset Prices, Consumption, and the Business Cycle." In Handbook of Macroeconomics, Volume 1, edited by J.B. Taylor and M. Woodford. Amsterdam: North-Holland.

Campbell, J. and J. Cochrane. 1999. "By Force of Habit: A Consumption-Based Explanation of Aggregate Stock Market Behavior." Journal of Political Economy 107: 205-51.

Campbell, J.Y. and R.J. Shiller. 1991. "Yield Spreads and Interest Rate Movements: A Bird's Eye View." Review of Economic Studies 58: 495-514.

Campbell, J.Y. and L.M. Viceira. 2001. "Who Should Buy Long-Term Bonds?" American Economic Review 91: 99-127.

Campbell, J.Y., A. Sunderam and L.M. Viceira. 2007. "Inflation Bets or Deflation Hedges? The Changing Risks of Nominal Bonds" Harvard University Working Paper.

Chapman, D.A. 2002. "Does Intrinsic Habit Formation Actually Resolve the Equity Premium Puzzle." Review of Economic Dynamics 5: 618-645.

Cochrane, J.H. 2001. Asset Pricing. Princeton, New Jersey: Princeton University Press.

Cochrane, J.H. and M. Piazzesi. 2005. "Bond Risk Premia." American Economic Review 95: 138-60.

Cox, J.C., J.E. Ingersoll, and S.A. Ross. 1985. "A Theory of the Term Structure of Interest Rates." Econometrica 53: 385-407.

Dai, Q. and K. Singleton. 2000. "Specification Analysis of Affine Term Structure Models." Journal of Finance 55: 1943-1978.

Dai, Q. and K. Singleton. 2002. "Expectation Puzzles, Time-varying Risk Premia, and Affine Models of the Term Structure." Journal of Financial Economics 63: 415-441.

Dai, Q. and K. Singleton. 2003. "Term Structure Modeling in Theory and Reality." Review of Financial Studies 16: 631-78.

Diebold, F.X., G. Rudebusch, and S.B. Aruoba. 2006. "The Macroeconomy and the Yield Curve: A Dynamic Latent Factor Approach." Journal of Econometrics 131: 309-338. 
Donaldson, J.B., T. Johnsen, and R. Mehra. 1990. "On the Term Structure of Interest Rates." Journal of Economic Dynamics and Control 14: 571-596.

Duffee, G.R. 2002. "Term Premia and Interest Rate Forecasts in Affine Models." Journal of Finance 57, 405-43

Duffie, D. and R. Kan. 1996. "A Yield-Factor Model of Interest Rates." Mathematical Finance 6: 379-406.

Egorov, A.V., Y. Hong, and H. Li. 2006. "Validating Forecasts of the Joint Probability Density of Bond Yields: Can Affine Models Beat Random Walk?" Journal of Econometrics 135: 255-284.

Epstein, L. 1983. "Stationary Cardinal Utility and Optimal Growth under Uncertainty." Journal of Economic Theory 31: 133-152.

Epstein, L. 1987. "A Simple Dynamic General Equilibrium Model." Journal of Economic Theory 41: 68-95.

Epstein, L. and S. Zin. 1989. "Substitution, Risk Aversion and the Temporal Behavior of Consumption and Asset Returns: A Theoretical Framework." Econometrica 57: 937-69.

Epstein, L. and S. Zin. 1991. "Substitution, Risk Aversion, and the Temporal Behavior of Consumption and Asset Returns: An Empirical Analysis." Journal of Political Economy 99: $263-286$.

Fama, E.F. and R.R. Bliss. 1987. "The Information in Long-Maturity Forward Rates." American Economic Review 77: 680-92.

Gallmeyer, M.F., B. Hollifield, and S. Zin. 2005. "Taylor Rules, McCallum Rules and the Term Structure of Interest Rates." Journal of Monetary Economics 52: 921-950.

Garcia, R, R. Luger, and E. Renault. 2003. "Empirical Assessment of an Intertemporal Option Pricing Model with Latent Variables." Journal of Econometrics 116: 49-83.

Gregory, A.W. and G.M. Voss. 1991. "The Term Structure of Interest Rates: Departures from Time-Separable Expected Utility." Canadian Journal of Economics 24: 923-939.

Hall, R. 1988. "Intertemporal Substitution in Consumption." Journal of Political Economy 96: 221-273.

Hördahl, P., O. Tristani, and D. Vestin. 2006. "A Joint Econometric Model of Macroeconomic and Term Structure Dynamics." Journal of Econometrics 131: 405-444. 
Kugler, P. 1997. "Central Bank Policy Reaction and the Expectations Hypothesis of the Term Structure." International Journal of Finance and Economics 2: 217-224.

Litterman, R. and J. Scheinkman. 1991. "Common Factors Affecting Bond Returns." Journal of Fixed Income 1: 54-61.

Litterman, R., J. Scheinkman, and L. Weiss. 1991. "Volatility and the Yield Curve." Journal of Fixed Income 1: 49-53.

Malloy, C.J., T.J. Moskowitz, and A. Vissing-Jørgensen. 2006. "Long-Run Stockholder Consumption Risk and Asset Returns." Northwestern University Working Paper.

Mankiw, G.N. and S. Zeldes. 1991. "The Consumption of Stockholders and Non-Stockholders." Journal of Financial Economics 29: 97-112.

McCallum, B.T. 1994. "Monetary Policy and the Term Structure of Interest Rates." NBER Working Paper No. 4938.

Mehra, R. and E. Prescott. 1985. "The Equity Premium Puzzle." Journal of Monetary Economics 15: 145-161.

Melino, A. and A.X. Yang. 2003. "State-Dependent Preferences can Explain the Equity Premium Puzzle." Review of Economic Dynamics 6: 806-30.

Mendoza, E. 1991. "Real Business Cycles in a Small-Open Economy." American Economic Review 81: 797-818.

Nalewaik, J.J. 2006. "Current Consumption and Future Income Growth: Synthetic Panel Evidence." Journal of Monetary Economics 53: 2239-2266.

Obstfeld, M. 1981. "Macroeconomic Policy, Exchange-Rate Dynamics, and Optimal Asset Accumulation." Journal of Political Economy 89: 1142-1161.

Obstfeld, M. 1990. "Intertemporal Dependence, Impatience, and Dynamics." Journal of Monetary Economics 26: 45-75.

Otrok, C., B. Ravikumar, and C. Whiteman. 2002. "Habit Formation: A Resolution of the Equity Premium Puzzle?" Journal of Monetary Economics 49: 1261-1288.

Piazzesi, M. 2005. "Affine Term Structure Models." In Handbook of Financial Econometrics, edited by Y. Ait-Sahalia and L. Hansen. Amsterdam: Elsevier-North Holland.

Piazzesi, M. and M. Schneider. 2006. "Equilibrium Yield Curves." NBER Macroeconomics Annual. 
Rudebusch G. and T. Wu. 2004. "A Macro-Finance Model of the Term Structure, Monetary Policy, and the Economy." Federal Reserve Bank of San Francisco Working Paper No. 2003-17.

Schmitt-Grohé, S. 1998. "The International Transmission of Economic Fluctuations: Effects of U.S. Business Cycles on the Canadian Economy." Journal of International Economics 44: $257-287$.

Schwartz, E. and W.N. Torous. 1999. "Can we Disentangle Risk Aversion from Intertemporal Substitution in Consumption." UCLA Working Paper.

Uribe, M. 1997. "Exchange-Rate-Based Inflation Stabilization: The Initial Real Effects of Credible Plans." Journal of Monetary Economics 39: 197-221.

Uzawa, H. 1968. "Time Preference, the Consumption Function, and Optimal Asset Holdings." In Capital and Growth: Papers in Honour of Sir John Hicks, edited by J.N. Wolfe. Chicago: Aldine.

Vasicek, O. 1977. "An Equilibrium Characterization of the Term Structure." Journal of Financial Economics. 5: 177-188.

Vissing-Jørgensen, A. 2002. "Limited Asset Market Participation and the Elasticity of Intertemporal Substitution." Journal of Political Economy 110: 825-853.

Wachter, J.A. 2006. "A Consumption-Based Model of the Term Structure of Interest Rates." Journal of Financial Economics 79: 365-99.

Weil, P. 1989. "The Equity Premium Puzzle and the Risk-Free Rate Puzzle." Journal of Monetary Economics 24: 401-421. 
Table 1. Summary Statistics of Yields Data

\begin{tabular}{llllllll}
\hline & \multicolumn{7}{c}{ Maturity in quarters } \\
\cline { 2 - 8 } & 1 & 2 & 4 & 8 & 12 & 16 & 20 \\
\hline Mean & 0.056 & 0.059 & 0.061 & 0.063 & 0.065 & 0.066 & 0.067 \\
Std. deviation & 0.028 & 0.028 & 0.027 & 0.027 & 0.026 & 0.025 & 0.025 \\
Skewness & 1.010 & 0.962 & 0.826 & 0.824 & 0.852 & 0.871 & 0.875 \\
Kurtosis & 4.474 & 4.298 & 3.886 & 3.712 & 3.664 & 3.597 & 3.478 \\
Min & 0.009 & 0.010 & 0.011 & 0.014 & 0.017 & 0.022 & 0.025 \\
Max & 0.151 & 0.159 & 0.155 & 0.154 & 0.151 & 0.150 & 0.145 \\
\hline
\end{tabular}

Note: The quarterly data set has 182 observations from 1959Q3 to 2004Q4. 
Table 2. Parameter Estimates: Equilibrium Model

\begin{tabular}{|c|c|c|c|c|c|}
\hline \multicolumn{6}{|c|}{ Non-expected utility case } \\
\hline \multicolumn{6}{|c|}{ Preference parameters } \\
\hline CRRA & $\begin{array}{c}6.057 \\
{[5.393,6.722]}\end{array}$ & & & & \\
\hline EIS & $\begin{array}{c}0.359 \\
{[0.297,0.421]}\end{array}$ & & & & \\
\hline \multicolumn{6}{|c|}{ Persistence matrix $\Phi$} \\
\hline Short rate & $\begin{array}{c}0.975 \\
{[0.346,1.604]}\end{array}$ & $\begin{array}{c}0.263 \\
{[-0.355,0.881]}\end{array}$ & $\begin{array}{c}-0.024 \\
{[-0.576,0.527]}\end{array}$ & $\begin{array}{c}0.101 \\
{[-0.498,0.699]}\end{array}$ & $\begin{array}{c}0.284 \\
{[-0.298,0.866]}\end{array}$ \\
\hline Spread & $\begin{array}{c}0.021 \\
{[-0.704,0.747]}\end{array}$ & $\begin{array}{c}0.804 \\
{[0.120,1.488]}\end{array}$ & 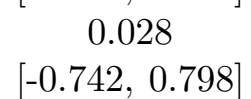 & $\begin{array}{c}-0.133 \\
{[-0.835,0.568]}\end{array}$ & $\begin{array}{c}-0.337 \\
{[-1.103,0.428]}\end{array}$ \\
\hline Market return & $\begin{array}{c}0.136 \\
{[-0.512,0.785]}\end{array}$ & $\begin{array}{c}1.067 \\
{[0.346,1.788]}\end{array}$ & $\begin{array}{c}0.126 \\
{[-0.542,0.795]}\end{array}$ & $\begin{array}{c}-0.625 \\
{[-1.215,-0.040]}\end{array}$ & $\begin{array}{c}-1.526 \\
{[-2.130,-0.923]}\end{array}$ \\
\hline Inflation & $\begin{array}{c}-0.020 \\
{[-0.749,0.708]}\end{array}$ & $\begin{array}{c}0.402 \\
{[-0.289,1.092]}\end{array}$ & $\begin{array}{c}0.042 \\
{[-0.616,0.700]}\end{array}$ & $\begin{array}{c}0.641 \\
{[0.017,1.267]}\end{array}$ & $\begin{array}{c}0.372 \\
{[-0.247,0.992]}\end{array}$ \\
\hline Consumption & $\begin{array}{c}0.046 \\
{[-0.291,0.383]}\end{array}$ & $\begin{array}{c}0.184 \\
{[-0.228,0.596]}\end{array}$ & $\begin{array}{c}0.025 \\
{[-0.283,0.334]}\end{array}$ & $\begin{array}{c}-0.242 \\
{[-0.578,0.093]}\end{array}$ & $\begin{array}{c}-0.409 \\
{[-0.718,-0.101]}\end{array}$ \\
\hline \multicolumn{6}{|c|}{ Expected utility case } \\
\hline \multicolumn{6}{|c|}{ Preference parameters } \\
\hline CRRA & $\begin{array}{c}2.747 \\
{[1.880,3.614]}\end{array}$ & & & & \\
\hline EIS & $\begin{array}{c}0.364 \\
{[0.249,0.478]}\end{array}$ & & & & \\
\hline \multicolumn{6}{|c|}{ Persistence matrix $\Phi$} \\
\hline Short rate & $\begin{array}{c}1.007 \\
{[0.457,1.556]}\end{array}$ & $\begin{array}{c}0.182 \\
{[-0.352,0.717]}\end{array}$ & $\begin{array}{c}0.009 \\
{[-0.421,0.440]}\end{array}$ & $\begin{array}{c}-0.006 \\
{[-0.560,0.548]}\end{array}$ & $\begin{array}{c}-0.063 \\
{[-0.686,0.558]}\end{array}$ \\
\hline Spread & $\begin{array}{c}-0.043 \\
{[-1.069,0.981]}\end{array}$ & $\begin{array}{c}0.881 \\
{[0.006,1.756]}\end{array}$ & $\begin{array}{c}-0.038 \\
{[-0.796,0.720]}\end{array}$ & $\begin{array}{c}-0.110 \\
{[-1.007,0.786]}\end{array}$ & $\begin{array}{c}-0.396 \\
{[-1.463,0.671]}\end{array}$ \\
\hline Inflation & $\begin{array}{c}0.608 \\
{[-0.326,1.543]}\end{array}$ & $\begin{array}{c}0.316 \\
{[-0.588,1.222]}\end{array}$ & $\begin{array}{c}0.402 \\
{[-0.530,1.335]}\end{array}$ & $\begin{array}{c}0.404 \\
{[-0.573,1.382]}\end{array}$ & $\begin{array}{c}0.515 \\
{[-0.474,1.506]}\end{array}$ \\
\hline Consumption & $\begin{array}{c}-0.226 \\
{[-1.097,0.645]}\end{array}$ & $\begin{array}{c}-0.121 \\
{[-1.109,0.867]}\end{array}$ & $\begin{array}{c}-0.156 \\
{[-1.133,0.819]}\end{array}$ & $\begin{array}{c}-0.271 \\
{[-1.088,0.545]}\end{array}$ & $\begin{array}{c}-0.449 \\
{[-1.357,0.459]}\end{array}$ \\
\hline
\end{tabular}

Notes: CRRA denotes the coefficient of relative risk aversion, EIS the elasticity of intertemporal substitution. The expected utility model restricts the CRRA to the reciprocal of the EIS so that the market return plays no contemporaneous role in the SDF. The numbers in square brackets are symmetric $95 \%$ confidence intervals. In the restricted case, the confidence limits for the EIS were found by the delta method. 
Table 3. VAR Estimation Results

\begin{tabular}{lccccc}
\hline \multicolumn{2}{l}{ Persistence matrix $\Phi$} & & & & \\
Short rate & 0.918 & 0.043 & 0.011 & 0.323 & 0.407 \\
& {$[0.859,0.978]$} & {$[-0.086,0.172]$} & {$[-0.007,0.029]$} & {$[0.091,0.554]$} & {$[0.139,0.675]$} \\
Spread & 0.025 & 0.842 & 0.004 & -0.117 & -0.267 \\
& {$[-0.016,0.068]$} & {$[0.750,0.934]$} & {$[-0.009,0.017]$} & {$[-0.282,0.048]$} & {$[-0.458,-0.076]$} \\
Market return & 0.096 & 0.865 & 0.175 & -0.274 & -1.628 \\
& {$[-0.393,0.586]$} & {$[-0.195,1.927]$} & {$[0.025,0.326]$} & {$[-2.182,1.633]$} & {$[-3.835,0.578]$} \\
Inflation & 0.024 & -0.078 & -0.002 & 0.779 & 0.231 \\
& {$[-0.003,0.052]$} & {$[-0.139,-0.018]$} & {$[-0.010,0.007]$} & {$[0.671,0.888]$} & {$[0.105,0.356]$} \\
Consumption & -0.008 & 0.056 & 0.009 & -0.102 & 0.208 \\
& {$[-0.040,0.024]$} & {$[-0.013,0.125]$} & {$[-0.001,0.019]$} & {$[-0.227,0.023]$} & {$[-0.063,0.353]$} \\
\hline
\end{tabular}

Notes: The entries are the estimation results from the macroeconomic data. The numbers in square brackets are symmetric $95 \%$ confidence intervals. 


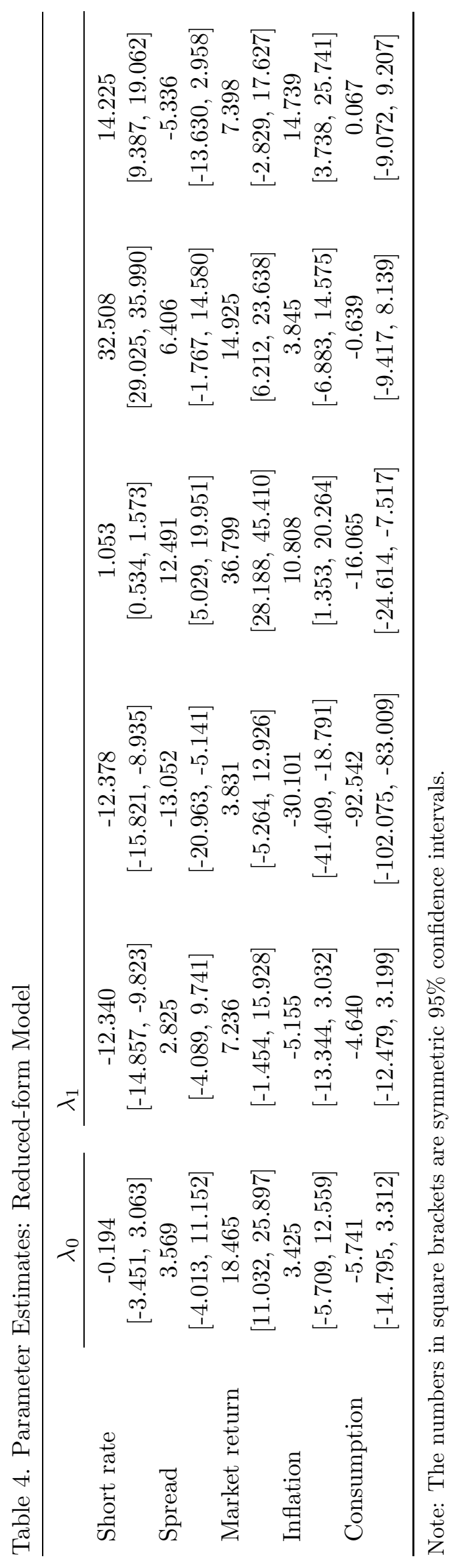


Table 5. In-Sample Absolute Pricing Errors (Basis Points)

\begin{tabular}{|c|c|c|c|c|c|}
\hline & \multicolumn{5}{|c|}{ Maturity in quarters } \\
\hline & 2 & 4 & 8 & 12 & 16 \\
\hline \multicolumn{6}{|c|}{ Equilibrium model } \\
\hline \multicolumn{6}{|c|}{ Non-expected utility case } \\
\hline Mean & 13.20 & 19.94 & 16.36 & 11.91 & 7.45 \\
\hline Std. dev. & 12.50 & 17.03 & 13.70 & 9.39 & 6.23 \\
\hline Min & 0.02 & 0.36 & 0.09 & 0.01 & 0.12 \\
\hline Max & 72.15 & 104.88 & 71.51 & 47.19 & 37.74 \\
\hline \multicolumn{6}{|c|}{ Expected utility case } \\
\hline Mean & 25.74 & 28.07 & 25.03 & 18.61 & 13.66 \\
\hline Std. dev. & 18.38 & 22.14 & 19.47 & 14.75 & 11.85 \\
\hline Min & 0.25 & 0.31 & 0.25 & 0.01 & 0.11 \\
\hline Max & 87.70 & 139.46 & 112.66 & 70.98 & 64.55 \\
\hline \multicolumn{6}{|c|}{ Reduced-form model } \\
\hline Mean & 14.55 & 20.56 & 16.93 & 13.72 & 12.36 \\
\hline Std. dev. & 12.26 & 17.38 & 13.19 & 10.68 & 9.34 \\
\hline Min & 0.42 & 0.34 & 0.05 & 0.16 & 0.34 \\
\hline Max & 75.22 & 107.98 & 70.31 & 53.61 & 47.79 \\
\hline
\end{tabular}

Note: The absolute pricing errors are calculated over the 182 quarterly observations for each of the 5 maturities that are not assumed to be priced without any sampling error. The 1 - and 20-quarter yields are priced without error. The expected utility model restricts the CRRA to the reciprocal of the EIS. 
Table 6. Variance Decompositions: Non-Expected Utility Model

\begin{tabular}{|c|c|c|c|c|c|}
\hline & \multicolumn{5}{|c|}{ Forecast horizon (quarters) } \\
\hline & 4 & 8 & 20 & 40 & $\infty$ \\
\hline \multicolumn{6}{|l|}{ 2-quarter yield } \\
\hline Short rate & 90.29 & 84.76 & 80.31 & 79.40 & 79.29 \\
\hline Spread & 0.79 & 1.24 & 1.35 & 1.30 & 1.29 \\
\hline Market return & 1.87 & 2.19 & 2.20 & 2.18 & 2.18 \\
\hline Inflation & 2.33 & 5.41 & 8.41 & 9.07 & 9.15 \\
\hline Consumption & 4.72 & 6.40 & 7.73 & 8.05 & 8.09 \\
\hline \multicolumn{6}{|l|}{ 4-quarter yield } \\
\hline Short rate & 87.30 & 82.12 & 78.25 & 77.51 & 77.42 \\
\hline Spread & 3.39 & 3.46 & 2.90 & 2.63 & 2.59 \\
\hline Market return & 2.24 & 2.49 & 2.41 & 2.36 & 2.35 \\
\hline Inflation & 2.60 & 5.85 & 8.93 & 9.60 & 9.68 \\
\hline Consumption & 4.47 & 6.08 & 7.51 & 7.90 & 7.96 \\
\hline \multicolumn{6}{|l|}{ 8-quarter yield } \\
\hline Short rate & 78.36 & 75.42 & 73.92 & 73.78 & 73.77 \\
\hline Spread & 12.83 & 10.32 & 6.96 & 5.96 & 5.84 \\
\hline Market return & 2.65 & 2.86 & 2.64 & 2.55 & 2.54 \\
\hline Inflation & 2.87 & 6.36 & 9.56 & 10.24 & 10.32 \\
\hline Consumption & 3.29 & 5.04 & 6.92 & 7.47 & 7.53 \\
\hline \multicolumn{6}{|l|}{ 12-quarter yield } \\
\hline Short rate & 70.57 & 70.24 & 71.01 & 71.40 & 71.45 \\
\hline Spread & 21.21 & 15.90 & 9.93 & 8.32 & 8.13 \\
\hline Market return & 2.87 & 3.05 & 2.76 & 2.64 & 2.62 \\
\hline Inflation & 2.85 & 6.45 & 9.75 & 10.45 & 10.53 \\
\hline Consumption & 2.50 & 4.36 & 6.55 & 7.19 & 7.27 \\
\hline \multicolumn{6}{|l|}{ 16-quarter yield } \\
\hline Short rate & 65.52 & 67.00 & 69.31 & 70.03 & 70.12 \\
\hline Spread & 26.63 & 19.42 & 11.72 & 9.72 & 9.48 \\
\hline Market return & 2.97 & 3.13 & 2.81 & 2.68 & 2.66 \\
\hline Inflation & 2.79 & 6.44 & 9.81 & 10.52 & 10.60 \\
\hline Consumption & 2.09 & 4.01 & 6.35 & 7.05 & 7.14 \\
\hline
\end{tabular}

Note: The entries are the percentage contribution of the $i$ th factor to the $h$-step-ahead forecast of the bond yield. 
Table 7. Variance Decompositions: Expected Utility Model

\begin{tabular}{|c|c|c|c|c|c|}
\hline & \multicolumn{5}{|c|}{ Forecast horizon (quarters) } \\
\hline & 4 & 8 & 20 & 40 & $\infty$ \\
\hline \multicolumn{6}{|l|}{ 2-quarter yield } \\
\hline Short rate & 90.50 & 84.97 & 80.43 & 79.49 & 79.38 \\
\hline Spread & 0.63 & 1.10 & 1.26 & 1.22 & 1.21 \\
\hline Market return & 1.79 & 2.16 & 2.18 & 2.17 & 2.16 \\
\hline Inflation & 2.09 & 5.20 & 8.29 & 8.97 & 9.05 \\
\hline Consumption & 4.99 & 6.57 & 7.84 & 8.15 & 8.20 \\
\hline \multicolumn{6}{|l|}{ 4-quarter yield } \\
\hline Short rate & 89.16 & 83.55 & 79.25 & 78.40 & 78.30 \\
\hline Spread & 1.96 & 2.29 & 2.11 & 1.96 & 1.93 \\
\hline Market return & 2.06 & 2.36 & 2.32 & 2.29 & 2.28 \\
\hline Inflation & 2.45 & 5.66 & 8.74 & 9.41 & 9.49 \\
\hline Consumption & 4.37 & 6.14 & 7.58 & 7.94 & 8.00 \\
\hline \multicolumn{6}{|l|}{ 8-quarter yield } \\
\hline Short rate & 83.79 & 79.18 & 76.18 & 75.69 & 75.64 \\
\hline Spread & 7.41 & 6.46 & 4.73 & 4.15 & 4.07 \\
\hline Market return & 2.12 & 2.51 & 2.44 & 2.38 & 2.38 \\
\hline Inflation & 2.87 & 6.28 & 9.40 & 10.07 & 10.14 \\
\hline Consumption & 3.81 & 5.57 & 7.25 & 7.71 & 7.77 \\
\hline \multicolumn{6}{|l|}{ 12-quarter yield } \\
\hline Short rate & 74.93 & 73.16 & 72.63 & 72.71 & 72.73 \\
\hline Spread & 16.22 & 12.43 & 8.05 & 6.83 & 6.67 \\
\hline Market return & 2.33 & 2.72 & 2.58 & 2.49 & 2.48 \\
\hline Inflation & 3.11 & 6.64 & 9.80 & 10.47 & 10.54 \\
\hline Consumption & 3.41 & 5.05 & 6.94 & 7.50 & 7.58 \\
\hline \multicolumn{6}{|l|}{ 16-quarter yield } \\
\hline Short rate & 64.83 & 66.82 & 69.26 & 69.99 & 70.08 \\
\hline Spread & 26.34 & 18.91 & 11.38 & 9.45 & 9.22 \\
\hline Market return & 2.45 & 2.86 & 2.67 & 2.56 & 2.55 \\
\hline Inflation & 3.18 & 6.78 & 10.00 & 10.67 & 10.75 \\
\hline Consumption & 3.20 & 4.63 & 6.69 & 7.33 & 7.40 \\
\hline
\end{tabular}

Note: The entries are the percentage contribution of the $i$ th factor to the $h$-step-ahead forecast of the bond yield. The expected utility model restricts the CRRA to the reciprocal of the EIS. The market return is still a predictor of the other state variables in the VAR and hence still makes a contribution in forecasting future bond yields. 
Table 8. Variance Decompositions: Reduced-form Model

\begin{tabular}{|c|c|c|c|c|c|}
\hline & \multicolumn{5}{|c|}{ Forecast horizon (quarters) } \\
\hline & 4 & 8 & 20 & 40 & $\infty$ \\
\hline \multicolumn{6}{|l|}{ 2-quarter yield } \\
\hline Short rate & 90.00 & 84.54 & 80.19 & 79.30 & 79.19 \\
\hline Spread & 0.77 & 1.21 & 1.32 & 1.27 & 1.26 \\
\hline Market return & 1.92 & 2.21 & 2.21 & 2.19 & 2.18 \\
\hline Inflation & 2.50 & 5.56 & 8.49 & 9.14 & 9.22 \\
\hline Consumption & 4.81 & 6.48 & 7.79 & 8.10 & 8.15 \\
\hline \multicolumn{6}{|l|}{ 4-quarter yield } \\
\hline Short rate & 86.91 & 81.90 & 78.13 & 77.41 & 77.33 \\
\hline Spread & 3.28 & 3.42 & 2.88 & 2.61 & 2.57 \\
\hline Market return & 2.35 & 2.56 & 2.44 & 2.39 & 2.38 \\
\hline Inflation & 2.65 & 5.89 & 8.94 & 9.61 & 9.68 \\
\hline Consumption & 4.81 & 6.23 & 7.61 & 7.98 & 8.04 \\
\hline \multicolumn{6}{|l|}{ 8-quarter yield } \\
\hline Short rate & 77.33 & 74.85 & 73.63 & 73.54 & 73.53 \\
\hline Spread & 12.74 & 10.29 & 6.96 & 5.98 & 5.86 \\
\hline Market return & 2.79 & 2.92 & 2.67 & 2.58 & 2.56 \\
\hline Inflation & 3.05 & 6.48 & 9.60 & 10.27 & 10.35 \\
\hline Consumption & 4.09 & 5.46 & 7.14 & 7.63 & 7.70 \\
\hline \multicolumn{6}{|l|}{ 12-quarter yield } \\
\hline Short rate & 68.00 & 68.69 & 70.21 & 70.74 & 70.80 \\
\hline Spread & 22.16 & 16.52 & 10.29 & 8.63 & 8.43 \\
\hline Market return & 3.00 & 3.09 & 2.78 & 2.66 & 2.64 \\
\hline Inflation & 3.39 & 6.85 & 9.94 & 10.60 & 10.67 \\
\hline Consumption & 3.45 & 4.85 & 6.78 & 7.37 & 7.46 \\
\hline \multicolumn{6}{|l|}{ 16-quarter yield } \\
\hline Short rate & 60.68 & 64.07 & 67.79 & 68.80 & 68.92 \\
\hline Spread & 29.34 & 21.15 & 12.66 & 10.51 & 10.24 \\
\hline Market return & 3.31 & 3.28 & 2.88 & 2.74 & 2.72 \\
\hline Inflation & 3.61 & 7.04 & 10.11 & 10.75 & 10.83 \\
\hline Consumption & 3.06 & 4.46 & 6.56 & 7.20 & 7.29 \\
\hline
\end{tabular}

Note: The entries are the percentage contribution of the $i$ th factor to the $h$-step-ahead forecast of the bond yield. 
Table 9. Out-of-Sample Absolute Pricing Errors (Basis Points)

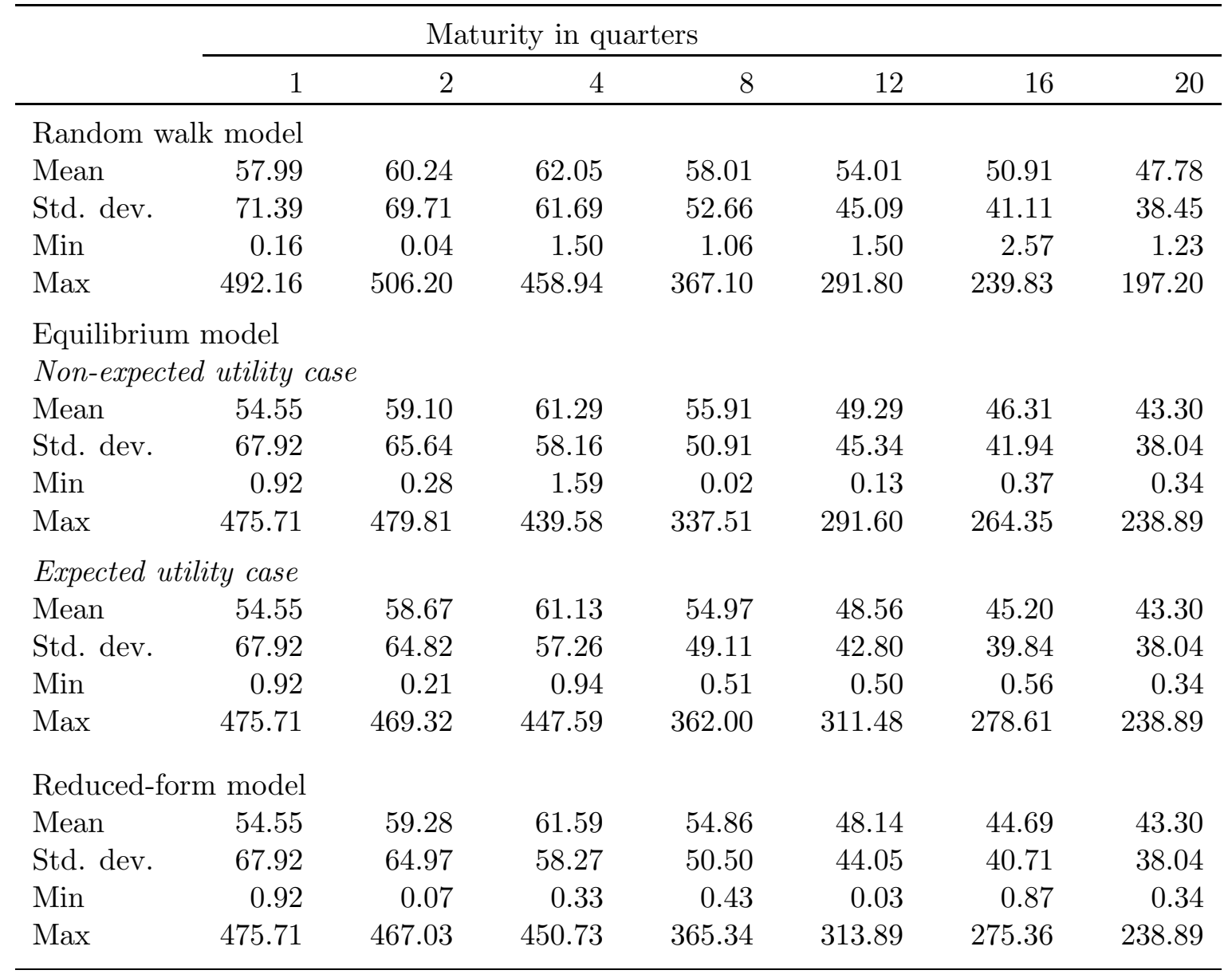

Note: The entries are one-quarter-ahead absolute forecast errors. The expected utility model restricts the CRRA to the reciprocal of the EIS. The forecasts from the benchmark random walk model are produced by simply assuming that future yields are equal to current yields. By construction, both versions of the equilibrium model and the reduced-form model have identical predictive abilities for 1 - and 20-quarter yields. 


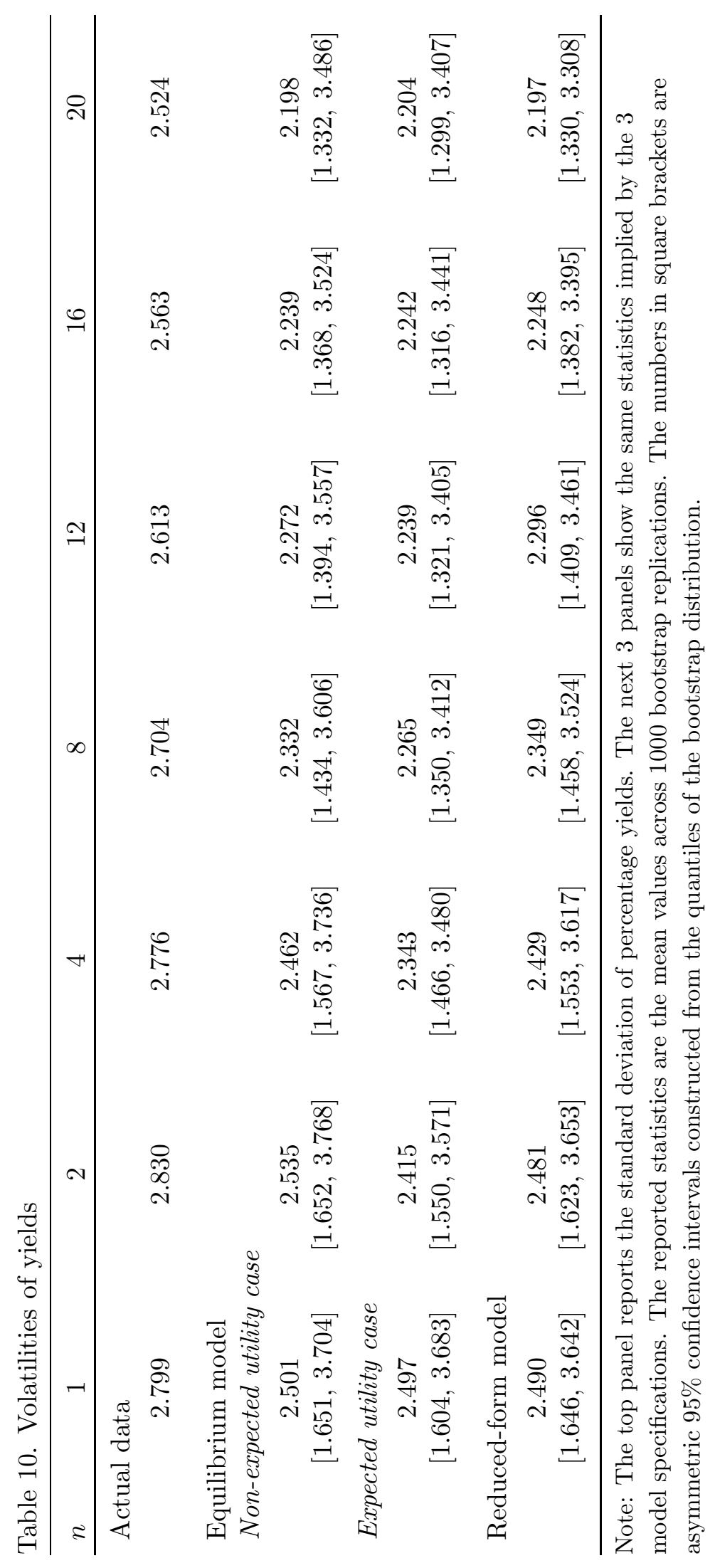




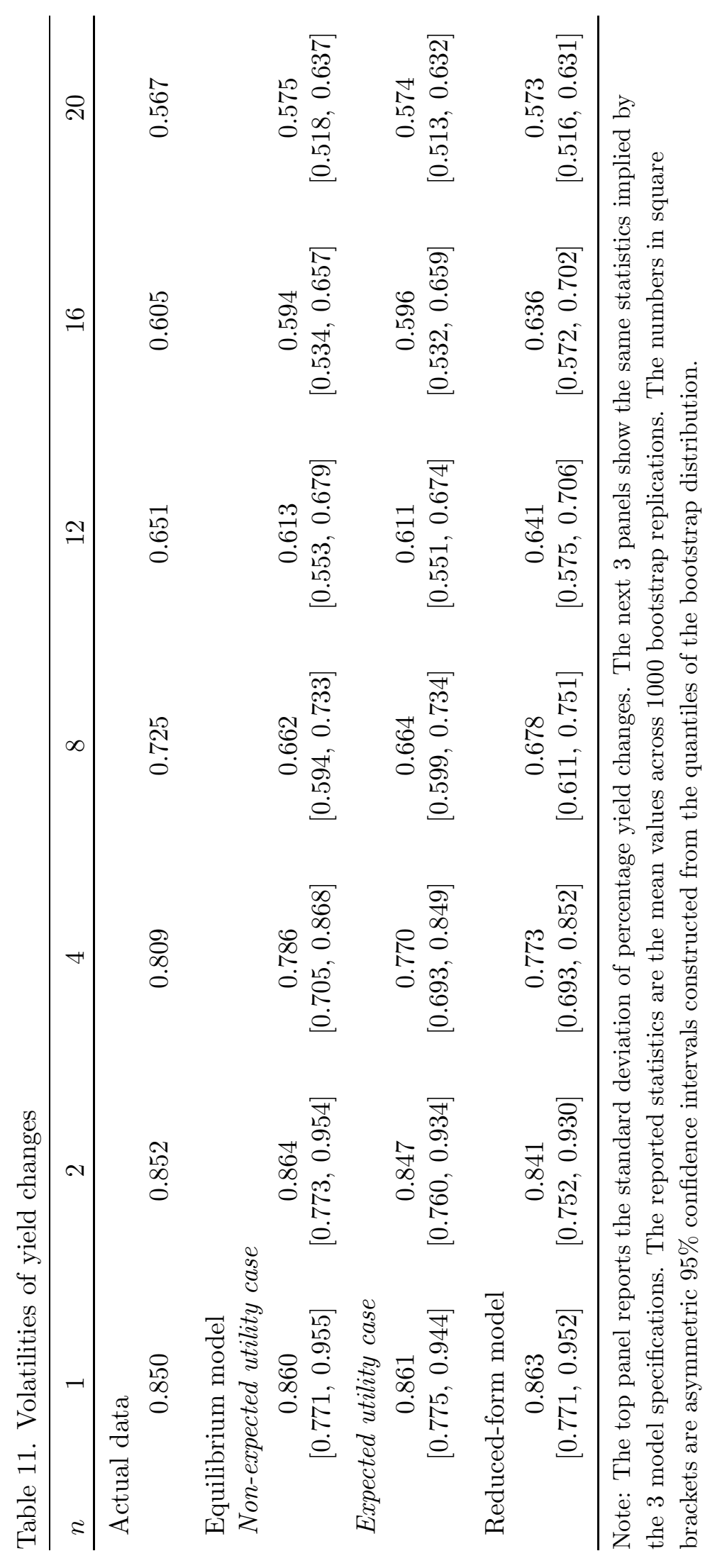


Table 12. Predictability of Yield Changes using Yield Spreads

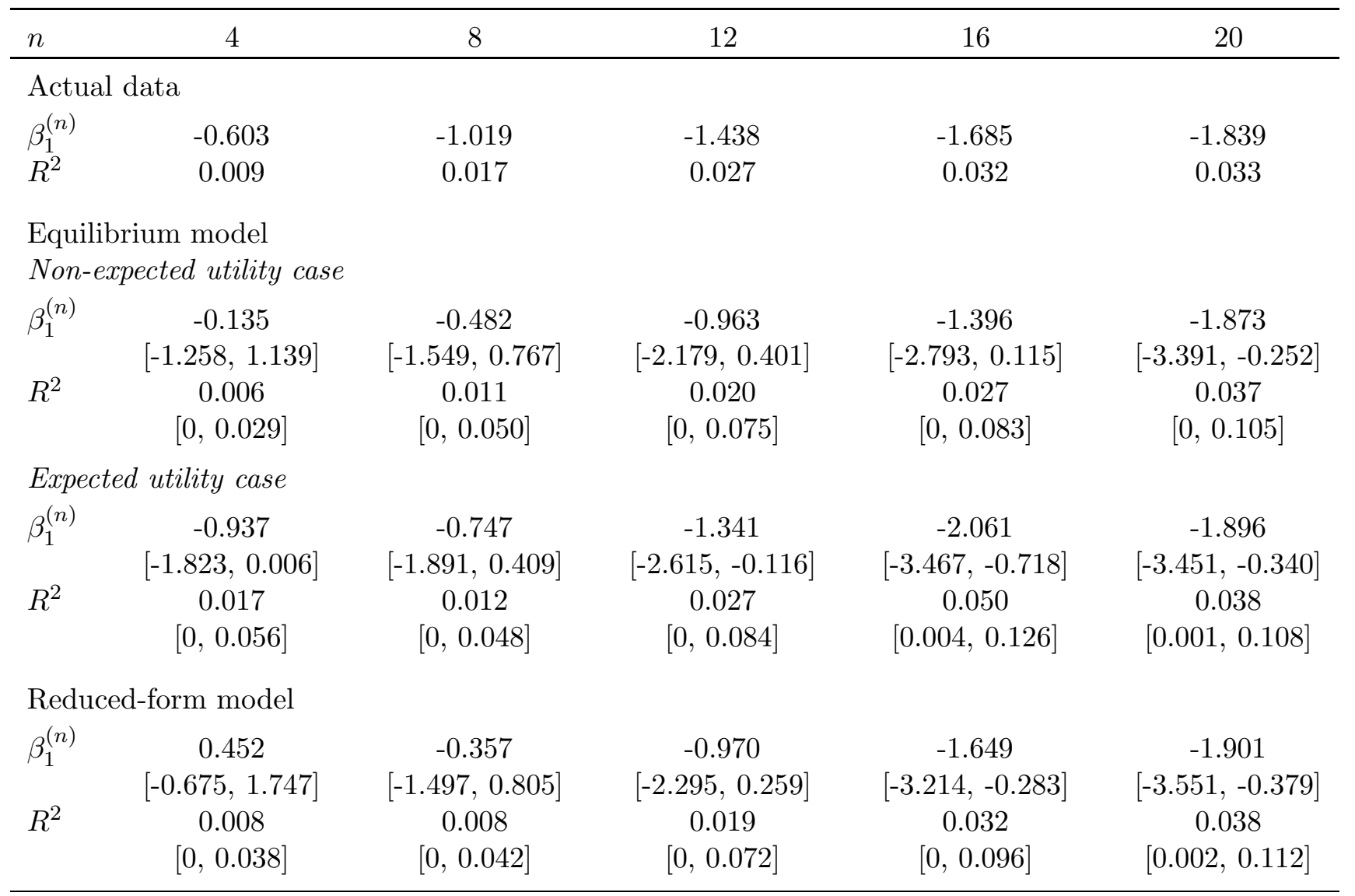

Note: The top panel reports the estimated slope coefficients and $R^{2}$ 's in the predictive regression of yield changes on yield spreads in (21). The next 3 panels show the same statistics implied by the 3 model specifications. The reported coefficients are the mean values across 1000 bootstrap replications. The numbers in square brackets are asymmetric $95 \%$ confidence intervals constructed from the quantiles of the bootstrap distribution. Values less than $10^{-3}$ are reported as zero. 
Table 13. Predictability of Excess Returns using Forward Rates

\begin{tabular}{|c|c|c|c|c|c|}
\hline$n$ & $\beta_{0}^{(n)}$ & $\beta_{1}^{(n)}$ & $\beta_{3}^{(n)}$ & $\beta_{5}^{(n)}$ & $R^{2}$ \\
\hline \multicolumn{6}{|c|}{ Actual data } \\
\hline 8 & -0.060 & -0.900 & 2.159 & -1.045 & 0.335 \\
\hline 12 & -0.089 & -1.823 & 4.408 & -2.287 & 0.362 \\
\hline 16 & -0.128 & -2.631 & 6.132 & -3.101 & 0.378 \\
\hline 20 & -0.168 & -3.216 & 7.139 & -3.438 & 0.366 \\
\hline
\end{tabular}

Equilibrium model

Non-expected utility case

$\begin{array}{cccccc}8 & -0.057 & -1.354 & 3.291 & -1.737 & 0.257 \\ & {[-0.139,-0.005]} & {[-2.349,-0.258]} & {[0.168,6.072]} & {[-3.712,0.411]} & {[0.080,0.446]} \\ 12 & -0.105 & -2.547 & 6.197 & -3.316 & 0.268 \\ & {[-0.246,-0.014]} & {[-4.305,-0.694]} & {[0.845,11.117]} & {[-6.770,0.414]} & {[0.096,0.455]} \\ 16 & -0.151 & -3.616 & 8.866 & -4.792 & 0.265 \\ & {[-0.352,-0.024]} & {[-6.107,-1.098]} & {[1.343,15.896]} & {[-9.622,0.471]} & {[0.100,0.446]} \\ 20 & -0.214 & -4.630 & 10.446 & -5.210 & 0.287 \\ & {[-0.482,-0.048]} & {[-7.803,-1.379]} & {[0.797,19.549]} & {[-11.551,1.564]} & {[0.113,0.482]}\end{array}$

Expected utility case

$\begin{array}{cccccc}8 & -0.051 & -0.458 & 0.972 & -0.303 & 0.210 \\ & {[-0.122,-0.004]} & {[-0.916,0.026]} & {[0.345,1.556]} & {[-0.624,0.046]} & {[0.071,0.380]} \\ 12 & -0.102 & -1.139 & 2.137 & -0.609 & 0.260 \\ & {[-0.225,-0.017]} & {[-1.982,-0.257]} & {[1.004,3.214]} & {[-1.181,0.005]} & {[0.106,0.442]} \\ 16 & -0.146 & -1.953 & 3.405 & -0.918 & 0.297 \\ & {[-0.324,-0.031]} & {[-3.115,-0.686]} & {[1.784,4.908]} & {[-1.729,-0.060]} & {[0.136,0.485]} \\ 20 & -0.188 & -2.385 & 3.197 & -0.190 & 0.270 \\ & {[-0.414,-0.040]} & {[-3.836,-0.739]} & {[1.162,5.107]} & {[-1.237,0.907]} & {[0.099,0.466]}\end{array}$

Reduced-form model

$\begin{array}{cccccc}8 & -0.083 & -0.498 & 0.586 & 0.204 & 0.241 \\ & {[-0.151,-0.031]} & {[-0.901,-0.032]} & {[-0.041,1.187]} & {[-0.261,0.687]} & {[0.074,0.420]} \\ 12 & -0.132 & -1.045 & 1.255 & 0.267 & 0.246 \\ & {[-0.261,-0.040]} & {[-1.760,-0.241]} & {[0.039,2.351]} & {[-0.569,1.124]} & {[0.077,0.418]} \\ 16 & -0.184 & -1.953 & 3.405 & -0.918 & 0.297 \\ & {[-0.376,-0.057]} & {[-2.633,-0.474]} & {[0.399,3.640]} & {[-1.055,1.334]} & {[0.079,0.415]} \\ 20 & -0.262 & -2.032 & 1.700 & 1.163 & 0.263 \\ & {[-0.514,-0.102]} & {[-3.293,-0.560]} & {[-0.424,3.672]} & {[-0.422,2.664]} & {[0.088,0.435]}\end{array}$

Note: The top panel reports the estimated coefficients and $R^{2}$ 's in the predictive regression of excess bond returns on forward rates in (22). The next 3 panels show the same statistics implied by the 3 model specifications. The reported coefficients are the mean values across 1000 bootstrap replications. The numbers in square brackets are asymmetric $95 \%$ confidence intervals constructed from the quantiles of the bootstrap distribution. 


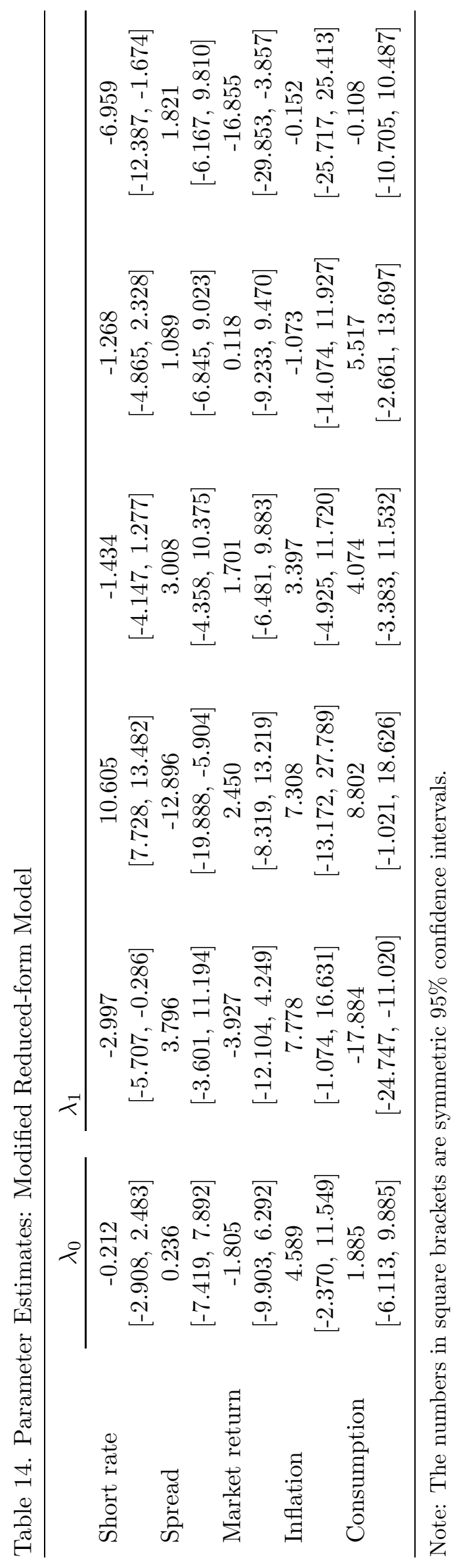


Table 15. Decomposition of Predictability Coefficients

\begin{tabular}{|c|c|c|c|c|c|c|c|}
\hline \multicolumn{4}{|c|}{$\left(X^{\prime} X\right)^{-1}$} & $X^{\prime} Y^{(8)}$ & $X^{\prime} Y^{(12)}$ & $X^{\prime} Y^{(16)}$ & $X^{\prime} Y^{(20)}$ \\
\hline \multicolumn{8}{|c|}{ Non-expected utility model } \\
\hline 0.081 & $\begin{array}{l}-0.221 \\
32.967\end{array}$ & $\begin{array}{c}0.890 \\
-97.163 \\
307.104\end{array}$ & $\begin{array}{c}-0.947 \\
66.505 \\
-216.936 \\
156.265\end{array}$ & $\begin{array}{l}3.161 \\
0.843 \\
1.087 \\
1.158\end{array}$ & $\begin{array}{l}4.647 \\
1.249 \\
1.658 \\
1.776\end{array}$ & $\begin{array}{l}5.423 \\
1.504 \\
2.035 \\
2.186\end{array}$ & $\begin{array}{l}5.626 \\
1.473 \\
2.208 \\
2.438\end{array}$ \\
\hline \multicolumn{8}{|c|}{ Reduced-form model } \\
\hline 0.075 & $\begin{array}{l}0.101 \\
4.646\end{array}$ & $\begin{array}{l}-0.142 \\
-6.189 \\
15.637\end{array}$ & $\begin{array}{c}-0.204 \\
1.743 \\
-9.647 \\
8.869\end{array}$ & $\begin{array}{l}1.950 \\
0.629 \\
0.843 \\
0.866\end{array}$ & $\begin{array}{l}5.383 \\
1.455 \\
1.930 \\
1.974\end{array}$ & $\begin{array}{l}5.774 \\
1.533 \\
2.163 \\
2.210\end{array}$ & $\begin{array}{l}5.007 \\
1.314 \\
2.069 \\
2.254\end{array}$ \\
\hline \multicolumn{8}{|c|}{ Modified reduced-form model } \\
\hline 0.097 & $\begin{array}{l}-0.301 \\
10.747\end{array}$ & $\begin{array}{c}1.888 \\
-38.860 \\
189.214\end{array}$ & $\begin{array}{c}-1.911 \\
29.594 \\
-157.299 \\
134.392\end{array}$ & $\begin{array}{l}2.808 \\
0.862 \\
1.094 \\
1.117\end{array}$ & $\begin{array}{l}4.484 \\
1.255 \\
1.699 \\
1.750\end{array}$ & $\begin{array}{l}5.803 \\
1.476 \\
2.114 \\
2.192\end{array}$ & $\begin{array}{l}5.207 \\
1.410 \\
2.181 \\
2.274\end{array}$ \\
\hline
\end{tabular}

Notes: The entries represent the decomposition of the estimated coefficients in the predictive regression of excess bond returns on forward rates in (22), expressed here in matrix form. The reported coefficients are the mean values across 1000 bootstrap replications. 
Figure 1. Subjective discount factor implied by the non-expected utility model.

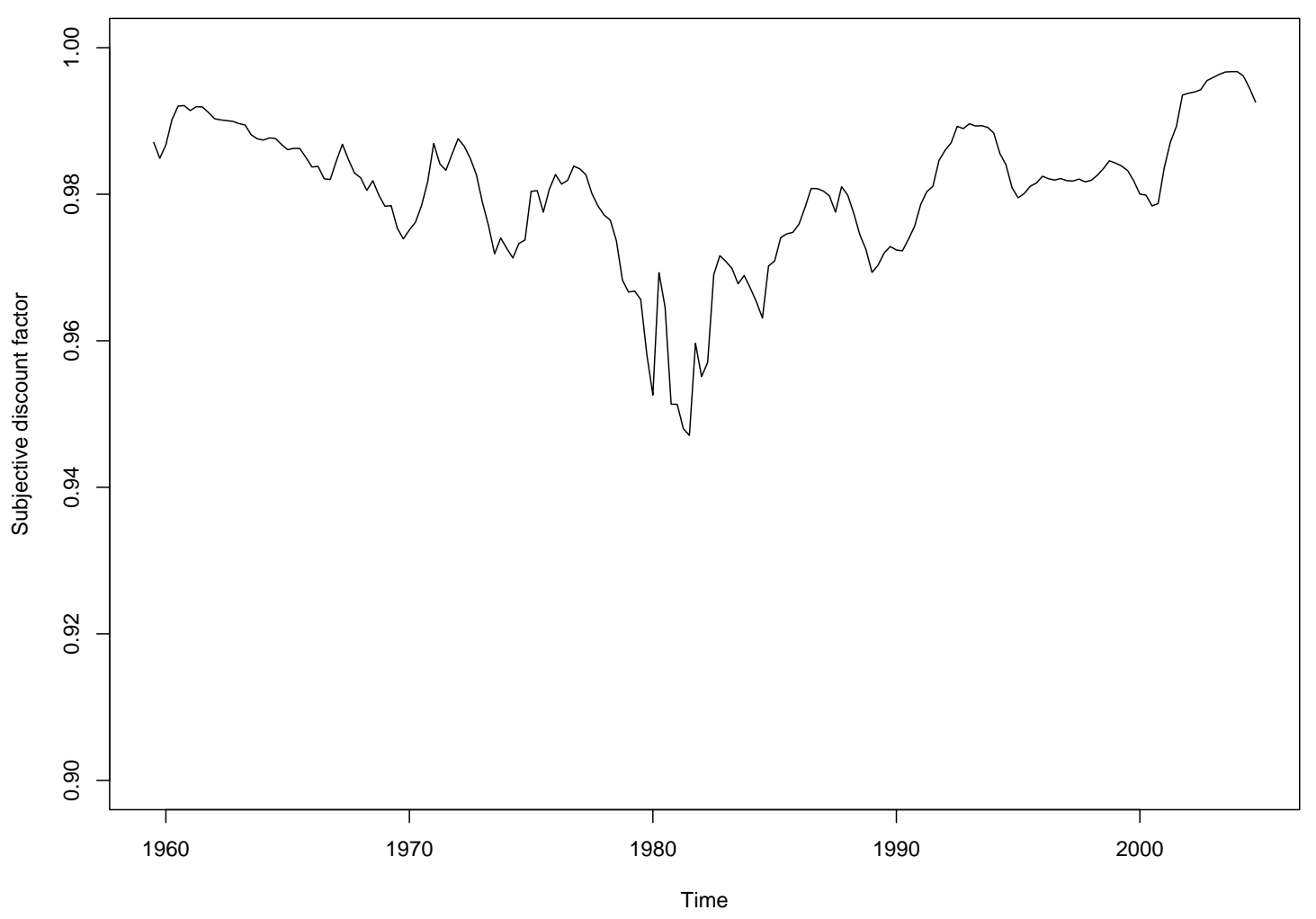



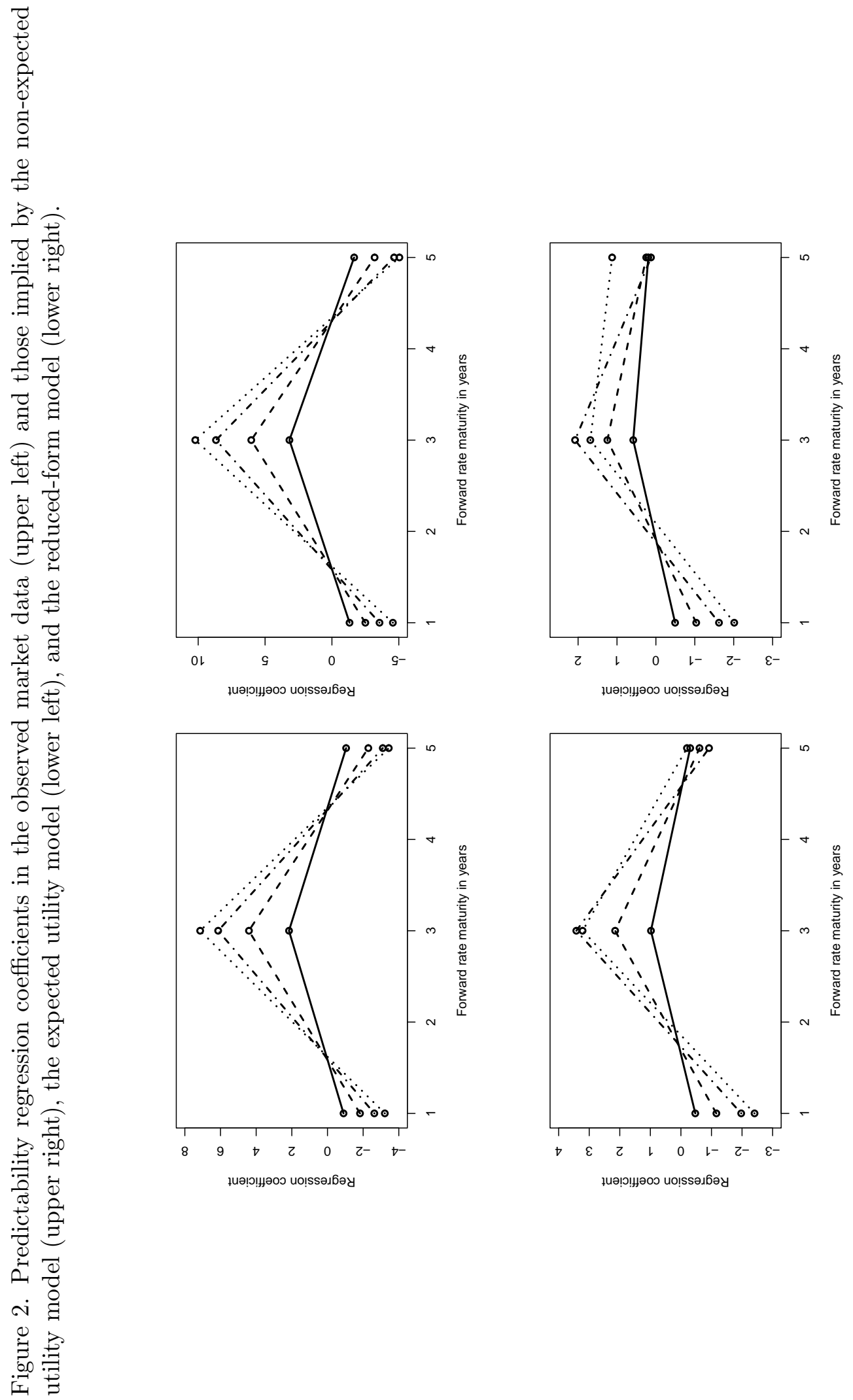

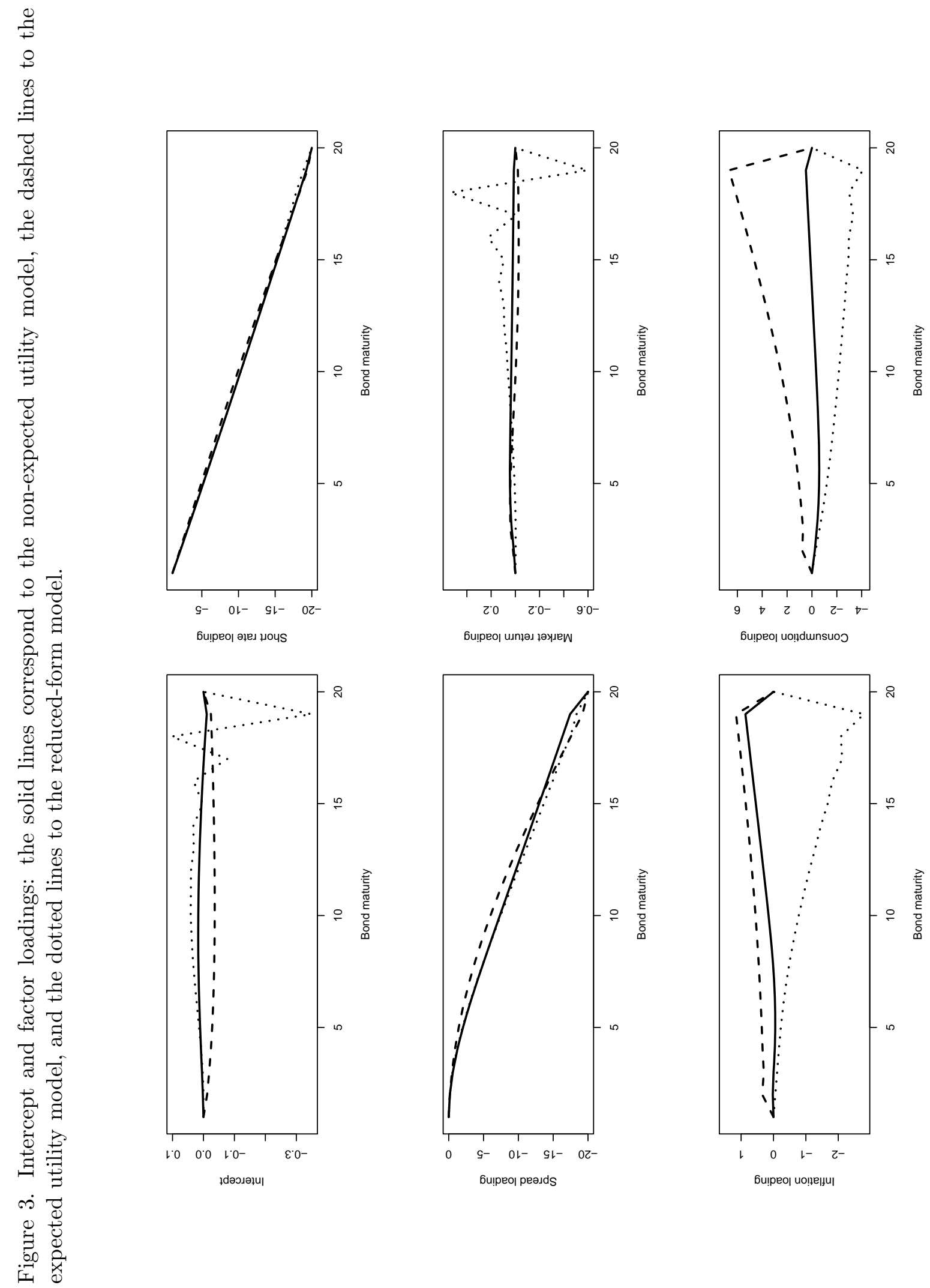
Figure 4. Innovation to the SDF of the non-expected utility model (top), the reduced-form model (middle), and the modified reduced-form model (bottom).
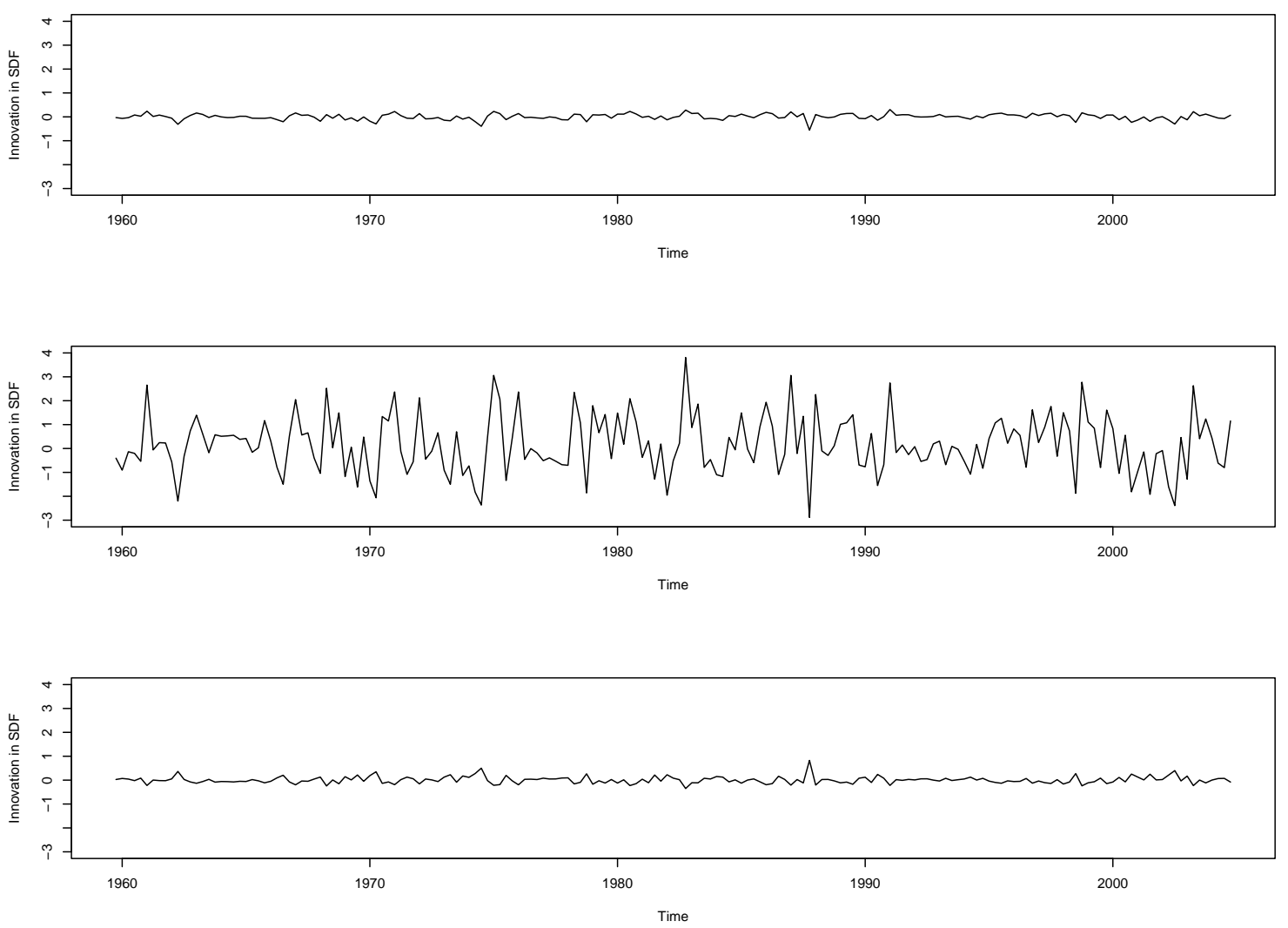
Figure 5. Predictability regression coefficients implied by the modified reduced-form model.

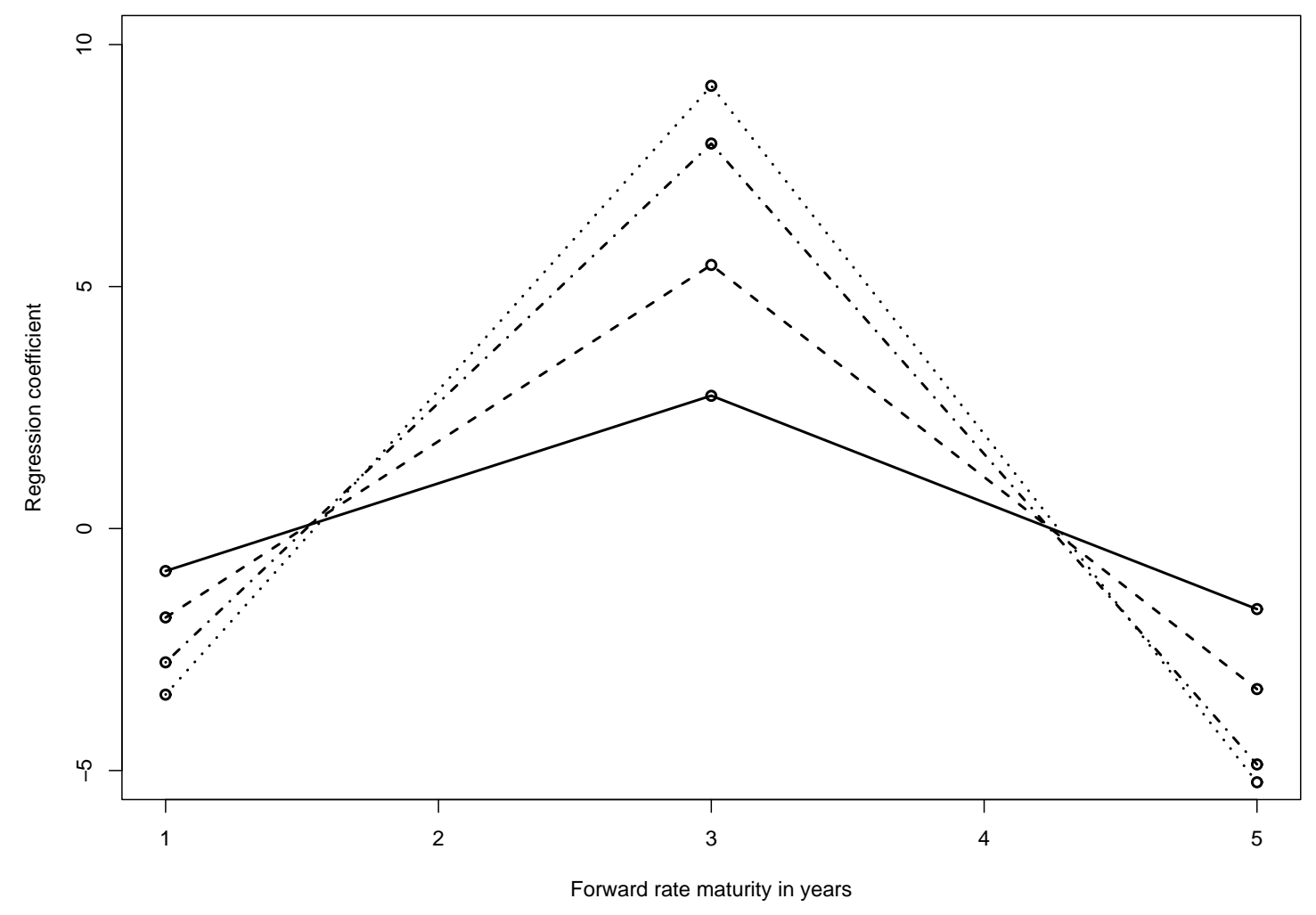

